Portland State University

PDXScholar

$1-1-2011$

\title{
Disordered Thought, Disordered Language: A corpus-based description of the speech of individuals undergoing treatment for schizophrenia
}

Lucas Carl Steuber

Portland State University

Follow this and additional works at: https://pdxscholar.library.pdx.edu/open_access_etds Let us know how access to this document benefits you.

\section{Recommended Citation}

Steuber, Lucas Carl, "Disordered Thought, Disordered Language: A corpus-based description of the speech of individuals undergoing treatment for schizophrenia" (2011). Dissertations and Theses. Paper 63.

https://doi.org/10.15760/etd.63

This Thesis is brought to you for free and open access. It has been accepted for inclusion in Dissertations and Theses by an authorized administrator of PDXScholar. Please contact us if we can make this document more accessible: pdxscholar@pdx.edu. 
Disordered Thought, Disordered Language:

A corpus-based description of the speech of

individuals undergoing treatment for schizophrenia

\author{
by \\ Lucas Carl Steuber
}

A thesis submitted in partial fulfillment of the requirements for the degree of

Master of Arts
in
Teaching English to Speakers of Other Languages

Thesis Committee:

Susan Conrad, Chair

Lynn Santelmann

Rik Lemoncello

Portland State University

(C)2011 


\begin{abstract}
The characteristics of patient speech are used in clinical settings to make assumptions about the thought processes of people with psychotic disorders such as schizophrenia. However, there have not been any studies of the language of people with schizophrenia that present evidence drawn from a large group of speakers. This study employs a combination of quantitative and qualitative methods to determine whether 140 medicated individuals diagnosed with schizophrenia exhibit the linguistic abnormalities claimed in the literature. It also compares the speech of people with schizophrenia with that of people diagnosed with depression in order to assess whether there is a statistically significant difference in presence and/or frequency of abnormal speech between the two groups. Ultimately this study finds that all of the specific types of abnormal language behavior described in the literature do occur among a large group of individuals with schizophrenia. However, many such behaviors also occur among individuals with depression; there was a significant difference between the two groups for three of the twelve categories of language features assessed in this study, which were peculiar word choice, illogicality and distractibility. Further characteristics of the language of individuals with schizophrenia were also found, which could be a basis for improving clinical diagnostic materials.
\end{abstract}




\section{Dedication}

This thesis is dedicated to my mother, who has given me unconditional love and support in every possible way and even a few that I thought were impossible.

It is also dedicated to Estelle, who is living proof that excess of speech is not an adequate diagnostic criteria for psychosis. 


\section{Acknowledgements}

From the beginning of my research as an undergraduate to the completion of this thesis I have been indebted to my supervisor, Dr. Susan Conrad of Portland State University, who has been an inexhaustible source of knowledge and enthusiasm. I have knocked on her door so many times that I suspect I have worn a shallow groove, and for that I am sorry.

I would like to thank Drs. Lynn Santelmann and Rik Lemoncello for serving on my thesis committee. I am extremely grateful to Dr. Santelmann for her continual unwillingness to tell me beautiful lies when called upon to provide feedback. I would also like to thank Jady Bates, the Linguistics department coordinator, for her procedural guidance and willingness to listen to me complain.

I am very grateful to Verilogue, Inc. and particularly cofounder Jamison Barnett for his gracious support. This sort of study would have been impossible without access to the data that Verilogue provided. Their professionalism and enthusiasm has been peerless throughout this process.

The support and encouragement of my friends and cohort has been indispensable, and I would like to particularly acknowledge (in no particular order) Estelle Konrad, Natalie West, Sara Jacoby, Martha Raab, Shannon Guinn-Collins, Azumi Stapp, Kylie Kim, Sara Lamadrid, Jessica Geil, and Henry and Amber Hoecker for keeping me on track or 
occasionally distracted, as necessary. I humbly ask forgiveness from all those who I've left out; hundreds of people have touched this thesis in some way.

Finally, I'd like to thank the various Steubers wandering the country, particularly my mother Midge, as well as Charlie, Vic, Carolyn and Robyn. Your support - emotionally, financially and otherwise - has been invaluable. I'd also like to thank my grandfather for being a constant source of inspiration, although he is wandering somewhere else entirely. 


\section{Table of Contents}

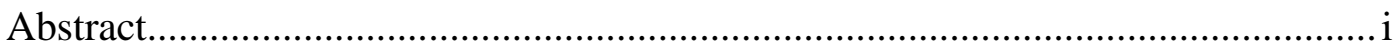

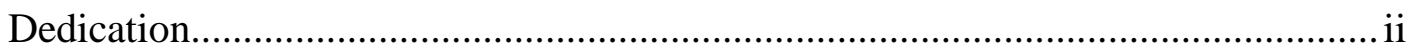

Acknowledgements.........................................................................................ii

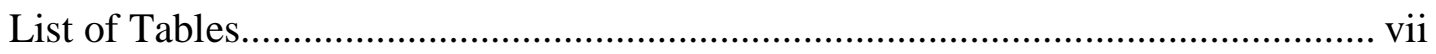

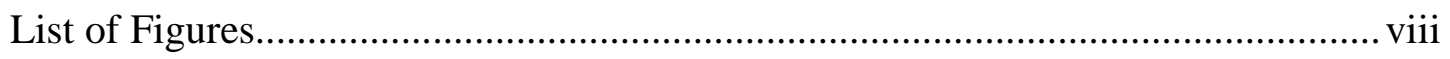

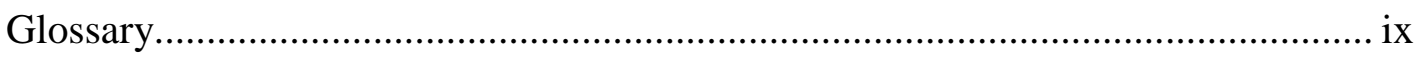

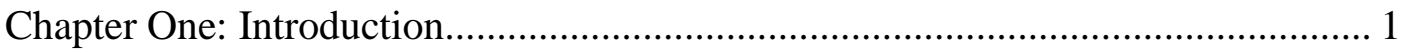

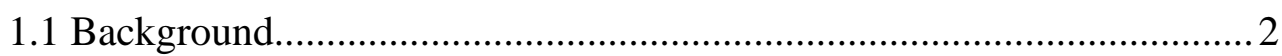

1.2 Types of Schizophrenia and the Patients in this Study.......................... 3

1.3 The Need for a Study of the Language of Schizophrenia........................ 4

Chapter Two: Literature Review...................................................................... 7

2.1 Overall Themes in Schizophrenic Language Research........................... 7

2.2 Specific Speech Disorders.................................................................. 10

2.3 Speech of Individuals with Depression................................................... 19

2.4 The Need for Large-Scale Studies........................................................ 20

2.5 Summary and Research Questions...................................................22

Chapter Three: Methodology............................................................................2 24

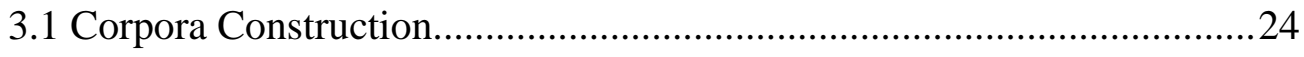

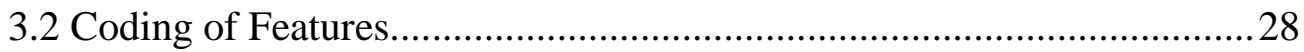

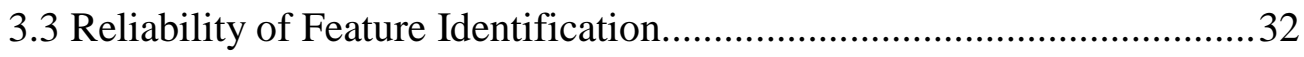

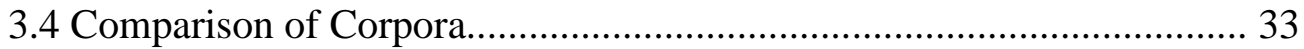


3.5 Conclusion................................................................................. 34

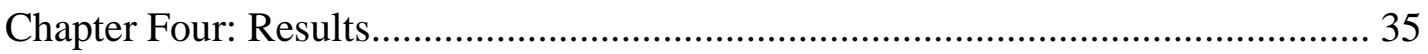

4.1 Overall Results............................................................................. 35

4.2 Results by Specific Speech Disorder.................................................... 36

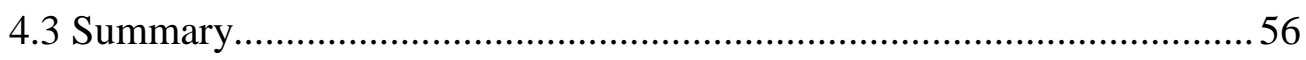

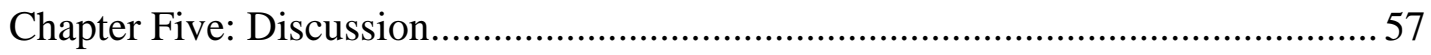

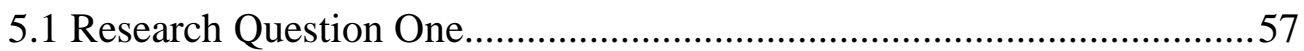

5.2 Research Question Two............................................................... 62

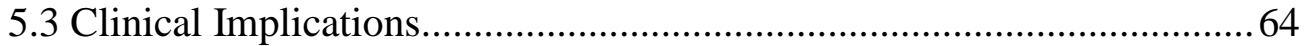

5.4 Limitations and Future Research..................................................... 68

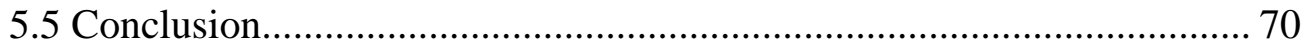

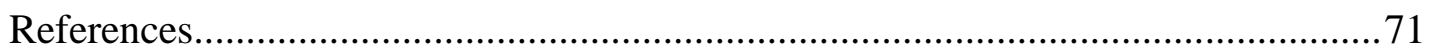




\section{List of Tables}

Table 1. Features of schizophrenic language as described in the literature............. 11

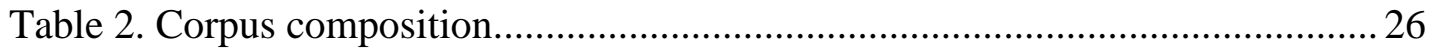

Table 3. Feature identification and coding.................................................... 29

Table 4. Results for disordered language features assessed for presence.............. 36

Table 5. Results for disordered language features assessed for frequency............ 39

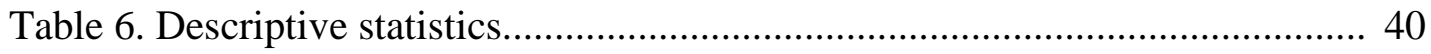

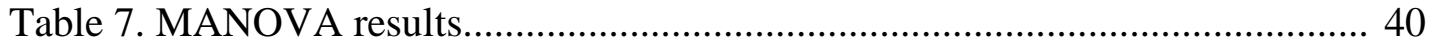

Table 8. Significance of MANOVA results by language feature $\ldots \ldots \ldots \ldots \ldots \ldots \ldots \ldots \ldots . . . \ldots 3$

Table 9. Suggested definitions of disordered language features..........................67 67 


\section{List of Figures}

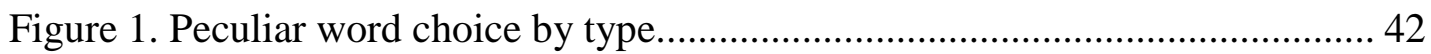

Figure 2. Distractibility by group and type................................................. 47

Figure 3. Sentence production by clause count............................................... 55 


\section{Glossary}

Alogia: Also referred to as "poverty of speech." Characterized by interactions or utterances that contain less than the expected amount of information.

Concordancer: A computer program designed to search for, sort, and display the context of words or phrases in an electronic database.

Disordered Language Feature: Any one of the abnormal forms of language production that have been described in literature regarding individuals with schizophrenia and/or are targeted in this study. For a complete list, see Table 1.

Echolalia: For the purpose of this study, this refers to the immediate repetition of a word or phrase uttered by a speaker's conversation partner. Delayed echolalia was not analyzed in this project.

Formal thought disorder: A term used to refer to the (unobservable) thought processes that motivate disordered language behavior.

Glossomania: Verbal production that seems to be motivated solely by a chain of semantic or phonetic assocations.

Neologism: A made-up word, or one that has no semantic value outside of that ascribed to it by the utterer.

Psychopharmacological Intervention: The use of psychoactive medication in order to alter one or more behaviors or thought processes.

Schizophrenia: A type of psychotic disorder characterized by the belief that one's thoughts and actions are externally controlled. 


\section{Chapter One: Introduction}

They were talking about something and I was just listening and I was tired. Then I started talking about like just, like nonsense, just stuff that has nothing to do with the conversation. ... It leaves me feeling confused, almost embarrassed.

Transcript 34223

The ability to communicate using spoken language is perhaps the most defining characteristic of humanity. Effective communication is the foundation for success in education, employment and social situations. What, then, is the implication for those who are incoherent? For the speaker in the quote above, they feel "confused, almost embarrassed," conscious of their errors but unable to correct their behavior. This is the hallmark of speech among individuals with schizophrenia: They will often be aware of, but lack control over, their own speech. Such individuals produce language that, consciously or unconsciously, deviates from its intended form. The purpose of this project is to test whether a subset of such deviations - which in this project (as in other research) will be referred to as "disordered language features" - are produced systematically among a large group of individuals with schizophrenia.

Schizophrenia, a neurological disorder that is estimated to affect roughly 70 million individuals worldwide, is primarily characterized by the feeling that one's thoughts and actions are externally controlled (Crow, 1997a, 1997b). It has been widely acknowledged in linguistic and psychological studies that those diagnosed with schizophrenia often produce abnormal linguistic output (Covington et al., 2005; 
American Psychiatric Association [DSM-IV-TR], 2000). For the past thirty years, the speech of people with schizophrenia has been studied and assessed to make predictions about the location of thought disorders within the human brain (see, for example, Crow, 1997a, 1997b) and to aid in the clinical diagnosis of schizophrenia (DSM-IV-TR, 2000; Morice \& Ingram, 1983; Reichenberg et al., 2002). Few studies have described the exact characteristics of the language of people with schizophrenia, and those that exist offer conclusions based on evidence from a small sample of individuals or present no evidence at all.

The purpose of this study is to determine the extent to which claims in literature about the language of people with schizophrenia are supported by an analysis of a large sample of affected individuals' speech. The speech of individuals diagnosed with schizophrenia will also be compared with the speech of individuals diagnosed with depression to determine whether such behaviors are shared between both groups. The goal of this research is to contribute to a more thorough understanding of the language features of individuals with schizophrenia, thus facilitating its clinical diagnosis.

The next sections of this chapter explain the background of my study and my personal motivation. Section 1.2 describes the various types of schizophrenia and the patients involved in this study. Section 1.3 positions this research among previous studies and briefly summarizes this project's purpose.

\subsection{Background}

Early in 2008 I approached a representative of Verilogue, Inc.

(http://www.verilogue.com/) seeking access to their transcripts of medical interactions for 
use in my thesis. They made a proposal: they would be willing to provide otherwise difficult to obtain language data from medical interactions if I was willing to co-author a related paper with one of their staff. Verilogue is a healthcare analytics company that specializes in the collection and analysis of interactions between doctors and patients across a variety of medical disciplines. Among their staff is a team of linguists with whom I am acquainted. Through agreements with the company I gained access to secondary data that would otherwise have been be exceptionally time consuming to obtain. The company has also obtained approval for working with human subjects and has navigated the legal terrain for working with doctors and medical facilities.

My interest in the language of people diagnosed with schizophrenia stems from a more general curiosity with abnormality in any field. I personally had no experience with schizophrenia and only passing knowledge of issues in mental health. As such, there is very little impact on this study from the perspective of the researcher; I came to this project as an inexperienced observer. In addition, Verilogue, Inc. expressed no expectations regarding the findings of my study, so there was no company mandate governing my research.

\subsection{Types of Schizophrenia and the Patients in this Study}

The American Psychiatric Association classifies schizophrenia as a "psychotic disorder," defining psychotic for these purposes as having "delusions, any prominent hallucinations, disorganized speech, or disorganized or catatonic behavior" (DSM-IV-TR, 2000, p. 297). In the same category as schizophrenia are schizophreniform disorders, which are temporary; schizoaffective disorder, in which psychotic behavior co-occurs 
with disordered emotions; delusional disorder, in which delusions occur without other symptoms of schizophrenia; and a variety of secondary psychotic disorders that are either brief in duration or triggered by other medical complications or substance abuse (DSM$I V-T R, 2000$, p.298). For the purpose of my study, the distinction between different types of psychotic disorders is not a major concern. What is important is the fact that they are each characterized by psychotic behavior, which includes disorganized speech. The individuals included in this study have been diagnosed with schizophrenia or depression by the psychiatrists who have provided transcripts to Verilogue, Inc.

It is important to note that the subjects of my study are under the influence of a variety of medications designed to treat schizophrenia and/or depression. The medications most frequently include (but are not limited to) Risperdal, Geodon, Abilify, Seroquel, Klonopin, Invega, Zyprexa, Lithium, Loxitane, Haldol, Clozaril, Depakote, Cogentin, Celexa and Wellbutrin. A description of the mitigating effects of these medications on disordered language behavior is well beyond the scope of my study. However, it should be noted that my research is rightly considered a description of the speech of medicated individuals with schizophrenia, and they are compared with the speech of medicated individuals with depression. While this is somewhat less than desirable, the use of speech samples from medicated individuals is common in the field.

\subsection{The Need for a Study of the Language of Schizophrenia}

Covington et al. (2005) suggest that computer-aided analysis of a large sample of the language of individuals with schizophrenia is strongly needed in order to clarify the nature of disordered speech among people with schizophrenia. This is the case not only 
because all previous studies of the language of individuals with schizophrenia have presented evidence from only a small number of speakers, but also because the features described by previous studies have been exceptionally diverse; no single study addresses all of the types of abnormal language that are found across the literature as a whole. An empirical study of such language as it is used in a natural setting would provide a principled account of all of the features that are potentially being used as diagnostic criteria in clinical settings. Corpus linguistics, which is primarily characterized by largescale computer-aided analyses of natural language, is uniquely suited to provide that account (Biber, Conrad \& Reppen, 1998). This study intends to fill the need for a largescale study by employing quantitative and qualitative methods to compare two corpora: one of the speech of individuals being treated for schizophrenia and one of the speech of individuals being treated for depression. Through examining this data it is possible to determine (1) whether the existence of the disordered language features described in the literature regarding the speech of people with schizophrenia are supported by language production among a large number of affected speakers and (2) whether those features, either individually or in combination, are unique to such speakers or if they are shared by individuals suffering from depression. This project expands the knowledge base regarding language disorders among people with schizophrenia by examining a data set that exceeds 160,000 words, several times larger and with more participants than any previous study.

One consideration regarding the validity of this study is the fact that the samples used in this study are drawn from individuals under the influence of medication. This implies that the types of abnormal language use found among the population of my study 
would not necessarily be found among unmedicated individuals with schizophrenia. However, medication has only been shown to reduce the production of subordinate propositions among people with schizophrenia (Levy, 1968), and even the most recent descriptions of the language of individuals with schizophrenia have been written using samples of the speech of medicated individuals (Liddle et al., 2002). Thus, while somewhat less than ideal, the use of samples drawn from medicated individuals with schizophrenia follows in the tradition of the field and remains useful for the purpose of revising existing descriptions which have generally studied a similar population.

Chapter two reviews previous studies of the speech of people with schizophrenia as well as studies that employed methodology similar to my own in order to lay the foundations for my study and establish its relevance. Chapter three describes the methods I employed in data gathering and analysis. Chapter four reports the results of my study, and chapter five states the results of my research questions and discusses the implications of my findings. 


\section{Chapter Two: Literature Review}

This chapter provides background necessary to understand the purpose and context of my study. I first address overall themes in research regarding the language of individuals with schizophrenia in order to establish the importance of understanding the nature of abnormal speech among people with schizophrenia. Section 2.2 then describes the individual linguistic disruptions caused by schizophrenia, according to previous literature. Section 2.3 reviews research regarding speech of individuals diagnosed with depression in order to introduce such speech as an adequate comparison. Section 2.4 examines similar large-population studies to establish that such methodology is appropriate, and section 2.5 briefly summarizes the chapter and lays out the research questions for my study.

\subsection{Overall Themes in Research}

According to the American Psychiatric Association, schizophrenia is a disorder characterized by "a range of cognitive and emotional dysfunctions that include perception, inferential thinking, language and communication, behavioral monitoring, affect, fluency and productivity of thought and speech, hedonic capacity, volition and drive, and attention" (2000, p. 299). While that is a lengthy list of symptoms, the most important characteristic of schizophrenia is disorganized thinking, and "because in a clinical setting inferences about thought are based primarily on the individual's speech, the concept of disorganized speech ... has been emphasized in the definition for schizophrenia" (p. 300). Speech, then, is a very important diagnostic criteria when 
treating individuals with schizophrenia. However, the specific characteristics of disorganized speech among people with schizophrenia have long been controversial.

Since at least the early 1970s, psychologists and linguists have been engaged in a debate about the characteristics, cause, and even existence of disordered language among people with schizophrenia. Brown (1973) argued that unusual language use among people with schizophrenia may not be due to any abnormality in linguistic subsystems, but that some aberrant mechanism of reality testing among such individuals causes them to deviate from typical beliefs and perceptions and, therefore, to produce abnormal language. This claim presupposes that there is such a thing as abnormal language output among people with schizophrenia, but for Brown such language is not rooted in patients' language capacity; rather, it is the result of a broader failure in perception. As Brown put it, "many authors who have written of schizophrenic language have intended what I will call thought, perhaps favoring the term language because it is closer to the observable behavioral level" (pp. 397-398).

Chaika (1974) acknowledged that "use of the term 'schizophrenic language' may be considered a methodological convenience" (p. 257). However, she argued that examining schizophrenic language is an effective way to study schizophrenic thought disorders, if only because language is observable while thought is not (Chaika, 1974; Chen et al., 1996). This claim is reflected in the DSM-IV-TR (2000), which states that "in a clinical setting inferences about thought are based primarily on the individual's speech" (p. 300). Thus, even if the term "schizophrenic language" is simply methodologically convenient, such speech is not only an effective way to study individuals' thought but is also being used as diagnostic criteria in clinical environments. 
Crow (1997a, 1997b) suggested that disordered language and disordered thought are inseparable and in fact that various types of psychoses, including schizophrenia, are a direct evolutionary result of the human capacity for language. His arguments are wideranging but hinge on the idea that neurophysiological abnormalities have been linked with various types of thought disorder. Some research supports this hypothesis. Morace and Ingram (1983) showed that syntactic complexity is permanently reduced by a factor relative to the age of onset of schizophrenia, suggesting that schizoid disorders exert influence on linguistic systems. Lecours and Vanier-Clément (1976) demonstrated that both thought and speech disorders among individuals with schizophrenia could be interrupted psychopharmacologically (a finding which will be discussed in the design of this study), and Condray, Steinhauer \& Goldstein (1992) showed that siblings of individuals with schizophrenia tended to exhibit similar symptoms of disorder in language comprehension, which suggests some sort of genetic tendency.

Whether abnormal speech among individuals with schizophrenia is a result of abnormal neurology, abnormal thought or abnormal linguistic processes, one point on which researchers agree is that people with schizophrenia do exhibit abnormal language (DSM-IV-TR, 2000). Of course, as Fromkin (1975) pointed out, abnormal linguistic output also occurs among the speech of "normal" individuals. This indicates that frequency of abnormality is likely to be a more effective criteria than presence of abnormality when evaluating disordered speech, a fact reflected in the design of this study.

Questions of neurophysiology and the nature of the connection between thought and speech are beyond the scope of this project, but such controversies highlight the need 
for an accurate description of the language of people with schizophrenia. Because psychiatrists use existing descriptions as diagnostic criteria for individuals who may be schizophrenic, a more complete description of the specific features of disordered language present among people with schizophrenia may aid researchers and medical practitioners by allowing them to more accurately identify and treat such individuals.

\subsection{Specific Speech Disorders}

This section will explore various accounts of the language of individuals with schizophrenia and attempt to build a unified list of the features that have previously been identified.

There have been at least four major attempts by linguists to describe the speech of individuals with schizophrenia and to identify the affected linguistic subsystems. Chaika's (1974) study was the first. It described six core characteristics of the speech of people with schizophrenia, and was supported by patient observations. Andraesen (1986) updated Chaika's criteria with her Thought, Language and Communication (TLC) scale, which remains the standard and most inclusive assessment instrument. Chen (1996) constructed a clinical rating instrument based on a simplified and modified version of TLC, and Liddle et al. (2002) provide the most recent update. While some of the recent scales provide supporting data, they rely primarily on accounts provided in previous literature and the clinical experience of the authors. All of the studies mentioned in this section addressed spoken language rather than written language where relevant.

Rather than describe each disordered language feature in detail (see Covington et al., 2005, for a comprehensive treatment), I will summarize the most widely discussed, a 
list of which can be found in Table 1. Few of the language features are mentioned in all four (or even three) of the existing models.

Table 1. Features of schizophrenic language as described in the literature.

\begin{tabular}{|c|c|}
\hline Affected Linguistic Subsystems & Feature \\
\hline Phonetics and Phonology & $\begin{array}{ll}- & \text { Aprosody (Covington et al., 2005) } \\
\text { - } & \text { Rhyming/Alliteration (Andraesen, 1986) } \\
\end{array}$ \\
\hline Morphology and Syntax & $\begin{array}{ll} & \text { Simple syntax (Morice \& Ingram, 1983) } \\
\text { - } & \text { Disrupted receptive syntax (Condray et al., 2002) }\end{array}$ \\
\hline Semantics and Lexicon & $\begin{array}{ll} & \text { Glossomania (Andraesen, 1986; Covington et al., 2005) } \\
\text { - } & \text { Peculiar word choice (Liddle et al., 2002; Covington et } \\
& \text { al., 2005) } \\
\text { - } & \text { Blocking (Andraesen, 1986; Covington et al., 2005) } \\
\text { - } & \text { Word salad (Covington et al., 2005; DSM-IV-TR, 2000) } \\
\end{array}$ \\
\hline $\begin{array}{l}\text { Pragmatics and Discourse } \\
\text { Competence }\end{array}$ & 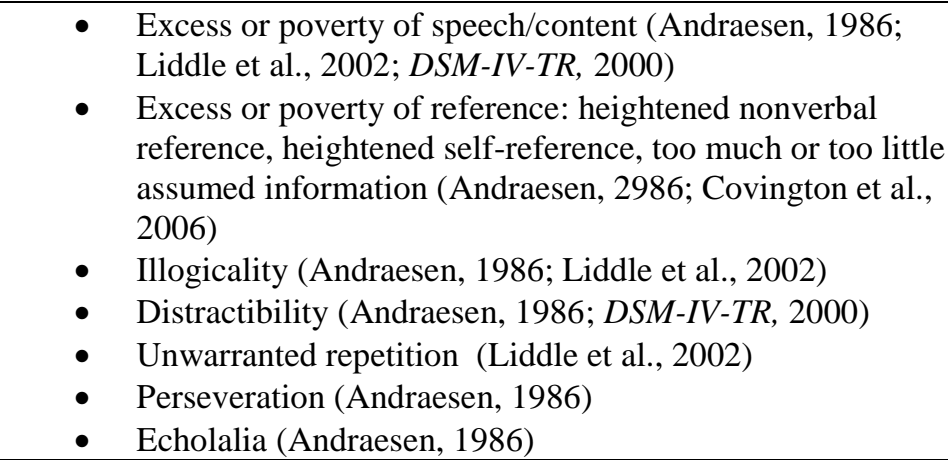 \\
\hline
\end{tabular}

\subsubsection{Phonetics and Phonology}

By most accounts, the phonological systems of people with schizophrenia are intact (Cohen, Nachmani \& Rosenberg, 1974; Covington et al., 2005). As Covington et al. (2005) note, "even the most unintelligible utterances conform to the arrangements of speech sounds permitted in the patient's language" (p. 9). Suprasegmentals, however, appear to be mildly disrupted; patients have been described as aprosodic, in that they produce flat intonation (Covington et al., 2005), and may become distracted by phonology, producing strings of rhymes or alliteration (Andraesen, 1986). Paradoxically, certain subjects have been shown to have difficulty naming lists of items that begin with 
a common letter (Gourovitch, Goldberg \& Weinberger, 1996), although that may be more an issue of lexical access, which I will address later, or a failure in working memory.

\subsubsection{Morphology and Syntax}

As with phonology, individuals with schizophrenia seem to have normal access to morphological and syntactic systems (Covington et al., 2005; Cohen, Nachmani \& Rosenberg, 1974). People with schizophrenia do not systematically produce syntactic errors, but they have been demonstrated to use simplified syntax in the form of frequent sentences with only one independent clause and fewer overall dependent clauses, particularly in cases of early onset schizophrenia (Covington et al., 2005; Morice \& Ingram, 1983). Condray et al. (2002) also found systematic disruptions in receptive syntax related to reading comprehension, although medication may have served as a confounding variable in that study.

\subsubsection{Semantics and Lexicon}

A great deal of the disruption described in the speech of individuals with schizophrenia has been described as lexical in nature, and appears to be an issue of access to lexicon rather than quantity of vocabulary (Andraesen, 1986; Gourovich, Goldberg \& Weinberger, 1996; Liddle et al., 2002; Covington et al., 2005). People with schizophrenia have been demonstrated to experience difficulty when asked to name lists of items beginning with a specific letter or belonging to a category, such as "animals" (Gourovich, Goldberg \& Weinberger, 1996). Paradoxically, however, they have also been observed repeating chains of words that are associated semantically or phonetically with no 
relevant context, a phenomenon known as glossomania or "clanging" (Andraesen, 1986;

Covington et al., 2005). Chaika (1974) offers an excerpt that captures both semantic and phonetic glossomania:

Patient: I have distemper just like cats do, 'cause that's what we all are, felines. Siamese cat balls. They stand out. I had a cat, a manx, still around here somewhere. You'll know him when you see him. His name is GI Joe; he's black and white. I had a little goldfish too, like a clown. Happy Halloween down. Down. (Chaika, 1974, p. 261)

In the example above the speaker makes a chain of semantic associations, moving from cats/felines to Siamese cat to the color of her cat, black and white. Either the color or the discussion of pets leads her to bring up her goldfish, like a clown (presumably striped/multicolored), where she begins to make a phonological association from clown to Halloween down to down. This phenomenon is termed glossomania because the speaker appears to have little or no control over the triggered associations and their vocalization.

Disorders of lexical access also manifest themselves in the form of word approximations, rare words, neologisms (entirely made-up words), and paraphasia (inappropriate word substitution) (Chaika, 1974; Andraesen, 1986; Covington et al., 2005). These disordered language features as a whole have been termed peculiar word choice (Liddle et al., 2002) and are discussed more frequently in the literature than glossomania. An example of each type of disordered lexical access follows.

Word Approximations

"His boss was a seeover" (for overseer) ～(Andraesen, 1986, p. 478)

This speaker has reversed the typical order of elements in the compound word "overseer." The meaning is clear, but the speaker's access to their vocabulary is somehow inhibited. 
$\underline{\text { Rare Words }}$

"I have been duped by inexpert dentistry" ～(Chaika, 1974, p. 267)

Rare words are somewhat subjective in their identification but are frequently found in clusters, such as the group of "duped" and "inexpert" in this utterance.

\section{Neologisms}

"I sort of bawked the whole thing up"

(Andraesen, 1986, p. 478)

Neologisms are also subjective in their identification; it can be difficult to distinguish between wholly made-up words and those that are common in a micro- or macrocultural lexicon. The example above, offered by Andraesen (1986), is a neologism in the sense that it does not appear in any dictionary.

\section{Paraphasia}

"Paperskate" (for "ballpoint pen") ～～(Andraesen, 1986, p. 478)

Paraphasia is a disorder that results in substitution of inappropriate words, perhaps a failure in the process that is otherwise known as circumlocution. In this case the speaker has created a compound word that simulates the behavior of the pen rather than the more accepted term based on its physical composition ("ballpoint").

Inhibited lexical access is often characterized by stilted speech, which frequently precedes peculiar word choice, and occasionally even blocking, wherein the speaker is entirely unable to complete an utterance (Andraesen, 1986; Covington et al., 2005). People with schizophrenia have also been shown to become more verbose but less accurate when asked to describe similar colors (Cohen, Nachmani \& Rosenberg, 1974), 
indicating a reliance on circumlocution. A similar issue is so-called word salad (DSM-IV$T R, 2000)$, in which any connection between meaning is either highly impaired or entirely lost:

Word Salad

"Oh, it was superb, you know, the trains broke, and the pond fell in the front doorway."

(Oh et al., 2002, p. 235)

As Covington et al. point out, it is difficult to determine whether there is any meaning associated with this statement; "is the patient actually expressing a thought of a pond falling in the front doorway" (2006, p. 13)? It seems more likely that there has been some sort of breakdown in this individual's conceptual relationship between words and their real-world counterparts.

\subsubsection{Pragmatics and Discourse Competence}

Literature discussing the speech of people with schizophrenia classifies the vast majority of abnormal output in the categories of pragmatics and discourse competence. This category encompasses disordered language that occurs as a result of discourse-level abnormality such as simply talking too much as well as features that are more straightforwardly pragmatic such as inappropriate behavior. Most notably, such speakers have been shown to demonstrate pressure of speech or excess of speech/content (Andraesen, N.C., 1986), in which speakers' overall word count is higher than would be expected. Paradoxically, individuals with schizophrenia also occasionally demonstrate poverty of speech or poverty of content, also referred to as alogia (Andraesen, N.C., 1986; Liddle et al., 2002; DSM-IV-TR, 2000); speakers either utter too few words or an adequate number of words with an inadequate quantity of information. Of course a great 
deal of variation in quantity of output occurs among normal speech, but some examples from my study were immediately exceptional:

Doctor: Eating enough?

Patient: Get food from the Army, I get, take home food, and buy milk. My brother bought me a whole, whole bunch of tea I said I needed, they didn't charge me for that, like it was, uh, not, $\$ 8.15$ for a box of Lipton Tea. [NAME OTHER], my brother's wife got it for about $\$ 2.50$ at Costco. So she got me a lot of tea. Tomorrow I go over there and paint a wall, paint it the second coat of a wall my, my brother's house because ...

Doctor: What about food [PATIENT NAME]?

(Transcript 34966)

The context of this short excerpt is a wellness check in which the psychiatrist is attempting to determine whether the patient is eating enough food. The patient responds by providing a large quantity of irrelevant material, demonstrating both excess of speech/content and a form of distractibility, which I will discuss later. Poverty of speech/content is normally characterized by a repeated paucity of expression throughout the course of an interaction, but some clear examples exist in a narrower context, such as the following taken from the transcripts I analyzed:

Doctor: Do you have any relationships like friends, anything?

Patient: Yeah. I have friends.

Doctor: Friends. Okay. You have a girlfriend, anything like that?

Patient: Friends.

(Transcript 34557)

The remainder of this individual's interaction with his physician consisted of one-word responses to prompts. In this case the patient is repeatedly providing less than the expected amount of information in response to questions, and never asks any questions of his own or voluntarily offers any content.

Another set of disordered language features are related to referents, namely heightened nonverbal reference (Covington et al. 2006), heightened self-reference 
(Andraesen, 1986), and overall obscurity of presumed information, in that speakers diagnosed with schizophrenia can either present too much background information or assume more knowledge on the part of the listener than is realistic (Andraesen, 1986; Covington et al., 2005). One example is as follows:

Patient: I get lonely. I get thinking about [NAME OTHER] and [NAME OTHER], and, you know, the life I could have had, and I just get depressed.

Doctor: [NAME OTHER], who?

(Transcript 31293)

In this interaction the patient mentioned the name of two individuals who had not previously been discussed in interactions with this doctor, citing her relationship with them as evidence for her depression. The doctor was forced to prompt her for additional information in order to contextualize the referents.

A related pragmatic disturbance is illogicality, characterized by faulty or inadequate logic (Andraesen, 1986; Liddle et al., 2002). The literature regarding schizophrenic speech makes no mention of intentional falsity, but people with schizophrenia - perhaps due to problems with presumed information, as mentioned above - seem to draw faulty conclusions from the most tenuous sources of evidence, for example:

Parents are the people that raise you. Anything that raises you can be a parent. Parents can be anything, material, vegetable, or mineral, that has taught you something. Parents would be the world of things that are alive, that are there. Rocks, a person can look at a rock and learn something from it, so that would be a parent. (Andraesen 1988, p. 478)

In this example the patient articulates a novel idea of parenthood, and in doing so transitions from a typical definition - "people that raise you" - into a less logical sequence 
of revisions that culminates with granting parenthood to inanimate objects. While there is certainly a type of sense to be made from this, it is more poetic than logical.

Individuals with schizophrenia are frequently discussed as being distractible (Andraesen, 1986; Liddle et al., 2002). Distractibility is typically classified into four specific categories: their speech can show tangentiality, in that they elaborate on irrelevant details; they can be derailed, meaning that they are easily distracted; they demonstrate loss of goal by losing track of the thread of discourse without outside interference; and they are circumstantial, in that they can be very indirect in their presentation of information (Andraesen, 1986; DSM-IV-TR, 2000). The following example shows distractibility that is both tangential and circumstantial:

Interviewer: What city are you from?

Patient: Well, that's a hard question to answer because my parents ... I was born in Iowa, but I know that I'm white instead of black so apparently I came from the North somewhere and I don't know where, you know, I really don't know where my ancestors came from. So I don't know whether I'm Irish or French or Scandinavian or I don't, I don't believe I'm Polish but I think I'm, I think I might be German or Welsh. I'm not but that's all speculation and that, that's one thing that I would like to know and is my ancestors, you know, where did I originate. But I just never took the time to find out the answer to that question.

(Andraesen, 1986)

In this example the patient does eventually provide something approximating the desired information but is very indirect in doing so and provides a great deal of unnecessary detail.

Behaviors that often co-occur with distractibility are unwarranted repetition, in which an individual repeatedly offers the same information during an interaction without being prompted to do so, and perseveration, where a speaker continues a conversational thread despite their interlocutor's attempts to dissuade them (Liddle et al., 2002; 
Andraesen, 1986). Another similar example is that of echolalia, in which the patient will repeat back phrases uttered by their interviewer (Andraesen, 1986), for example:

Doctor: Okay, so [PATIENT NAME], you've been hearing voices.

Patient: Yes, sir.

Doctor: Uh, is that, like, every day?

Patient: Not every day, yeah, every day, every -

Doctor: Every day.

Patient: Every, every ...

(Transcript 33918)

In the interaction above, the doctor speaks the words "every day," which are then repeated back four times by the patient in rapid succession. This type of echolalia is immediate, in that it occurs right after the triggering utterance and does not seem to recur throughout the interaction. My study does not treat delayed echolalia as separate from unwarranted repetition, although delayed echolalia has been found in the speech of individuals with schizophrenia (Andraesen, 1986).

\subsection{Speech of Individuals with Depression}

In the present study, individuals with depression are used as a comparison group against the group of individuals with schizophrenia. It is therefore important to consider whether there are features present in the speech of individuals with depression that could potentially co-occur in both groups. There has been a great deal of research regarding individuals with depression, but very little has focused specifically on language. One exception is Rude et al. (2004), who studied a corpus of the writing of depressed, formerly depressed and never depressed college students and identified three characteristics of depressive language. The depressed participants were more selfreferential and used more negatively valenced words and more words related to social 
processes than their never depressed (and formerly depressed) counterparts. This confirms and expands the findings of an earlier, related study, that employed the same methodology on a group of suicidal individuals (Stirman and Pennebaker, 2001).

Affect appears to be one area of overlapping dysfunction in both depressed individuals and people with schizophrenia, but as the DSM-IV-TR (2000) points out, "individuals with symptoms of depression typically experience an intensely painful affect, whereas those with Schizophrenia have a diminuition or emptiness of affect" (p. 301), although this claim is not explicitly based on language research. This project does not address the question of affect in language, so this distinction is worth noting only for the sake of completion. Heightened self-reference is another shared characteristic between the speech of depressed individuals and the speech of people with schizophrenia, but it is not a targeted language feature in this study. In sum, while there is evidence that there are overlapping language features between individuals with schizophrenia and those with depression - specifically, heightened self-reference and disordered affect - those features are excluded from this study.

\subsection{The Need for Large-Scale Studies}

Research regarding the speech of individuals with schizophrenia has usually been conducted with a small number of participants. In one of the first studies, Levy (1968) based his findings in interviews with four individuals diagnosed with schizophrenia, and even a larger-scale recent study (Condray et al., 2002) employed comprehension accuracy scores among a group of 32. Morice and Ingram (1983) studied syntactic complexity among 29 individuals with schizophrenia using specialized computer 
software and a collection of 1,000 word samples of speech. However, much of the research regarding schizophrenic speech presents either anecdotal evidence or no evidence at all. The unique advantage of a study using a large population is the ability to examine a much larger sample of the language of individuals with schizophrenia than any previous research.

The idea of using large samples to examine medical interactions is by no means a new one; Kokkinakis (2006) and Habert et al. (2001) are two recent international examples studying medical interactions in general using corpus linguistics. As described briefly in chapter one, corpus linguistics is a methodological framework that makes use of computers in order to analyze large bodies of natural text, or corpora (Biber et al., 1998). The idea of evaluating psychological diagnostic criteria via corpus linguistics is likewise not a new one, although it is a field still very much in development and limited to a few practitioners. Rude, Gortner and Pennebaker (2004), Stirman and Pennebaker (2001), Cohn, Mehl and Pennebaker (2004), and Pennebaker, Mehl and Niederhoffer (2003) are four widely cited examples addressing depression, suicide, catastrophic social change and psychological identity, respectively. The advantage that these studies - and my study - have over those that employ small bodies of evidence is primarily clarity of description. The use of qualitative analysis on a principled collection of speech allows for much less ambiguous description than those based on anecdotal evidence.

Finally, statistical analysis of a large body of speech allows for much more generalizable conclusions than those drawn from anecdotal evidence and small samples of speakers. While this study makes only limited use of techniques from corpus linguistics, the relatively large population studied in this project is a marked advantage 
over previous studies that have only analyzed the speech of small groups of individuals. Because large-scale studies of language have been of use in other areas of linguistics, it stands to reason that a large-scale study of the language of individuals with schizophrenia would be similarly fruitful.

\subsection{Summary and Research Questions}

A large number of claims have been made about the features of speech among people with schizophrenia, but these claims are not based on data from a study involving a large number of people with schizophrenia. Because these features are being used as diagnostic criteria by psychiatrists (see DSM-IV-TR, 2000), the language of individuals with schizophrenia is in need of an accurate description drawn from the speech of a large number of affected speakers. Furthermore, in order to ensure that such a description accurately identifies behaviors that are associated with people with schizophrenia, it is important to compare the speech of such individuals with that of a second group. Individuals with depression constitute an appropriate group for comparison because their speech has not been shown to share many characteristics with the speech of individuals with schizophrenia.

This study uses two corpora, one of the speech of individuals diagnosed with schizophrenia and one of the speech of individuals diagnosed with depression, to answer the following questions:

1. To what extent do a large number of individuals with schizophrenia exhibit the behaviors that have been described in small-scale studies of the speech of people with schizophrenia? 
2. Are the linguistic behaviors observed among patients being treated for schizophrenia significantly different from those observed among patients being treated for depression? 


\section{Chapter Three: Methodology}

This project analyzed the language of people with schizophrenia and compared it to the language of individuals with depression. In order to answer my research questions I constructed two corpora, coded transcripts of patients' speech for specific types of disordered language, and then performed statistical analyses. This chapter describes the methodology I employed to complete each step. Section 3.1 describes the construction of the corpus. Section 3.2 articulates the language features included in the study and the protocols used to code them. Section 3.3 discusses the measures taken to ensure reliability in the coding process, and section 3.4 explains the analytical and statistical procedures used to determine results.

\subsection{Corpora Construction}

As the first step in my study, I compiled two corpora: one of the speech of people diagnosed with schizophrenia, and one of the speech of people diagnosed with depression. 150 transcripts of interactions between doctors and patients diagnosed with schizophrenia and close to 1,000 transcripts of interactions between doctors and patients diagnosed with depression were provided by Verilogue, Inc. The disparity in the number of transcripts is due to availability of targeted diagnoses; schizophrenia is far less common than depression. While there are an estimated 7 million individuals worldwide with schizophrenia, there are an estimated 67 million individuals worldwide with depression (DSM-IV-TR, 2000). I will first discuss the overall construction of each corpus before exploring the details of each. 
For both corpora, each transcript consists of a single interaction between a doctor and patient in a psychiatric environment. The majority of interactions occur in the doctor's practice, but a few occur in group homes or other environments. In some cases a caretaker or nurse is also present during the interaction. All of the patients interviewed were undergoing some type of psychopharmacological intervention in the form of medication. As the design of this study makes it impossible to remove medication as an confounding variable, it is important to note that this is a study of the speech of medicated individuals with schizophrenia or depression, as mentioned in chapter one. As mentioned in chapter two, research indicates that medication may have an impact on production of disrupted speech. However, that impact has only been demonstrated in the case of subordinate clause production (Levy, 1968), and previous studies of the speech of individuals with schizophrenia have used samples of language from medicated speakers (Liddle et al., 2002). Further implications of the use of the speech of medicated individuals for this study are discussed in chapter five.

Each transcript in both corpora involves a unique patient. It is unlikely that a unique doctor is present in each of the interactions, but demographic information provided in each transcript (gender and length of practice) make it clear that there are a minimum of eight different physicians. More specific information regarding their identity is unavailable. Names and other potentially identifying data were removed by Verilogue prior to providing transcripts, which makes some variables impossible to assess. The education level and geographic region of the patients, for example, are unknown, as is the age of onset and duration of treatment. Many other facts are available, however, 
including their gender, race, approximate age, and any medications they are currently taking.

As gender and age were held constant between both corpora, the percentage of each subcategory in each group was roughly equal. Approximately $62 \%$ of the participants from each corpora were male. $20 \%$ of each group were between the ages of $55-74$, and approximately $26 \%$ were between the ages of $19-34$, with the remainder being 35-54. Both groups were mixed-race, including Caucasians, African Americans, Hispanics and Asian Americans, but the racial breakdown was not equivalent between corpora. A detailed composition of the final corpora is shown in table 2.

Table 2. Corpus Composition

\begin{tabular}{|l|l|l|}
\cline { 2 - 3 } \multicolumn{1}{l|}{} & Schizophrenia & Depression \\
\hline Interactions & 140 & 50 \\
\hline Words & 111,421 & 52,347 \\
\hline Age & & \\
$19-34$ & $36(25.71 \%)$ & $13(26 \%)$ \\
$35-53$ & $76(54.29 \%)$ & $27(54 \%)$ \\
$55-74$ & $28(20 \%)$ & $10(20 \%)$ \\
\hline Gender & & \\
Male & $86(61.43 \%)$ & $31(62 \%)$ \\
Female & $54(38.57 \%)$ & $19(38 \%)$ \\
\hline Race & & \\
Caucasian & $102(72.86 \%)$ & $42(84 \%)$ \\
African American & $32(22.89 \%)$ & $4(8 \%)$ \\
Hispanic & $3(2.14 \%)$ & $1(2 \%)$ \\
Asian American & $2(1.42 \%)$ & $3(6 \%)$ \\
Native American & $1(0.71 \%)$ & 0 \\
\hline
\end{tabular}

The first corpus I constructed was that of individuals with schizophrenia. Of the 150 transcripts involving people with schizophrenia, I ultimately decided to remove ten from my corpus. Two consisted primarily of interactions between doctors and patients' caretakers, and one was a scripted role-play that did not represent the authentic language production of an individual with schizophrenia. Four transcripts involving patients over 
the age of 75 and three involving patients under 18 were also removed in order to reduce the possibility of age-related language features affecting the analysis (see Coupland et al. 1991 and Bruner 1983 for examples of the impact of age on linguistic behavior).

I also constructed a comparison corpus of the speech of individuals diagnosed with depression who were involved in conversations with medical practitioners. This corpus was chosen due to the similar context of the interactions. A corpus of everyday speech or writing would simply not be an equivalent genre because the schizophrenia interactions occurred in a clinical environment. Similarly, it is impossible (or, minimally, very difficult) to find clinical interactions between mental health professionals and individuals who are not suffering from any type of mental illness. Additionally, as discussed in the literature review, there are very few types of abnormal speech behavior associated with depression, only one of which overlaps with a behavior among people with schizophrenia (poverty of speech). The speech of depressed individuals was therefore selected as the best option for comparison due to the similar clinical environment and the relative lack of abnormal speech behavior described in relevant literature.

For the depression corpus, fifty transcripts of the speech of individuals with depression were selected. I regarded that number as large enough to capture a good deal of variation among depression patients and to make statistical tests meaningful without being so large as to be unfeasibly time consuming. The corpus of speech of depressed individuals was constructed to mirror the gender and age in the corpus of individuals with schizophrenia, but was otherwise composed of transcripts selected at random. All 150 
schizophrenia transcripts and 50 depression transcripts were then stripped of their diagnosis information to ensure lack of bias while coding.

\subsection{Coding of Features}

Nineteen specific features of schizophrenic language described in the literature review were identified and coded. These features were separated into twelve different categories, as described in Table 3. Disordered language features mentioned in the literature that relate to phonology (aprosody, rhyming), semantic blocking, receptive syntax, and nonverbal reference were not analyzed because they cannot be evaluated using the transcripts provided. Affect and heightened self-reference were not analyzed in research question two because they were areas of potential overlap in disordered language features between individuals with schizophrenia and individuals with depression. Heightened self-reference was also not evaluated for research question one because it is a relative measure and is thus only profitably analyzed in comparison to another group, and no suitable option was available.

One category, inappropriateness, was added as a feature after coding a small number of transcripts. There were so many examples of insults, threats and profanity that it was logical (and interesting) to track them as a type of disordered language. Examples of inappropriate speech are explored in depth in section 4.2.2. For a complete list of features described in the literature, refer to Table 1.

The identification and coding protocol for each feature is described in Table 3 on the following page. 
Table 3. Feature Identification and Coding

\begin{tabular}{|c|c|}
\hline Name & Identification and Assessment \\
\hline \multicolumn{2}{|l|}{ Syntax } \\
\hline Simple Syntax & $\begin{array}{l}\text { Relative lack of dependent clauses. Presence of this feature was assessed by } \\
\text { examining number of clauses per sentence across a subset of the corpora, as } \\
\text { described in detail toward the end of this section. }\end{array}$ \\
\hline \multicolumn{2}{|l|}{ Semantics/Lexicon } \\
\hline Glossomania & $\begin{array}{l}\text { Frequency of this feature was assessed by coding excerpts in which patients } \\
\text { chain content until their output is irrelevant. Irrelevancy was evidenced by a } \\
\text { complete departure from the theme of their interlocutor's previous utterance or } \\
\text { the overall theme of the discourse. }\end{array}$ \\
\hline Peculiar Word Choice & $\begin{array}{l}\text { This category includes word approximations, rare words, neologisms and } \\
\text { paraphasia. A software concordancer was used to find the least commonly } \\
\text { occurring lexical items in the corpus. These infrequent words were then } \\
\text { categorized as one of the four types of peculiar word choice. }\end{array}$ \\
\hline Word Salad & $\begin{array}{l}\text { Presence of this feature was assessed by coding excerpts which could be heard } \\
\text { but not understood. }\end{array}$ \\
\hline \multicolumn{2}{|l|}{ Pragmatics } \\
\hline $\begin{array}{l}\text { Excess/Poverty of } \\
\text { Speech }\end{array}$ & $\begin{array}{l}\text { Presence of this feature was assessed by coding interactions in which patients' } \\
\text { output is significantly more or less than expected. This was evidenced by their } \\
\text { interlocutors' attempts to interrupt and redirect the discourse or prompt for } \\
\text { additional information, respectively. }\end{array}$ \\
\hline $\begin{array}{l}\text { Assumed Knowledge } \\
\text { (too little or too much) }\end{array}$ & $\begin{array}{l}\text { Frequency of this feature was assessed by coding transcript excerpts in which } \\
\text { referents were repeatedly introduced or remained unclear. }\end{array}$ \\
\hline Illogicality & $\begin{array}{l}\text { Utterances that draw conclusions based on faulty or inadequate logic. } \\
\text { Frequency of this feature was assessed by coding transcript excerpts in which } \\
\text { patients' conclusions are contextually unfounded or seem to be based on } \\
\text { information that their interlocutor does not share. }\end{array}$ \\
\hline Distractibility & $\begin{array}{l}\text { This category includes tangentiality, derailment, loss of goal and } \\
\text { circumstantiality. Frequency of these features was assessed by coding } \\
\text { transcript excerpts in which patients demonstrated one or more of the types of } \\
\text { distractibility as described in the literature review. }\end{array}$ \\
\hline Unwarranted Repetition & $\begin{array}{l}\text { Frequency of this feature was assessed by coding excerpts in which patients } \\
\text { repeat the same information multiple times in the same interaction without } \\
\text { prompting. }\end{array}$ \\
\hline Perseveration & $\begin{array}{l}\text { Frequency of this feature was assessed by coding excerpts in which patients } \\
\text { persist despite doctors' explicit attempts to silence or redirect them. }\end{array}$ \\
\hline Echolalia & $\begin{array}{l}\text { Focusing specifically on immediate echolalia, the frequency of this feature was } \\
\text { assessed by coding patient output that precisely repeated a word or phrase from } \\
\text { the doctor's previous turn. }\end{array}$ \\
\hline Inappropriateness & $\begin{array}{l}\text { Frequency of this feature was assessed by coding insults, threats, profanity and } \\
\text { other similarly inappropriate utterances. }\end{array}$ \\
\hline
\end{tabular}


Identification of the disordered language features listed above required some degree of judgment on the part of the reader. For this reason, I took a number of measures to ensure reliability during the coding process. I read every transcript in both corpora multiple times to ensure that I had accurately and consistently coded all of the features above. In addition, I conducted reliability checks on the coding process, detailed in section 3.3. As results are reported in chapter four, examples are provided that make it clear that the majority of these features are easily identifiable in most cases.

Each feature was assessed either on the basis of how many times they occurred overall (frequency) or whether it occurred even once in a transcript (presence). Items assessed for frequency were marked every time they occurred whereas items assessed for presence were assessed at the level of the overall transcript. This was the case for poverty and excess of speech, which exist not as a discrete occurrence but rather as a pattern of behavior over time. It is conceivable that the abnormalities described in Table 3 could occur as a result of simple speaker error, or that they might occur equally in both corpora. For this reason frequency data were collected whenever such analysis was feasible. This made it possible to compare individuals undergoing treatment for schizophrenia and individuals undergoing treatment for depression not only on the basis of whether they exhibit disruption of linguistic subsystems in a way that is consistent with the literature concerning schizophrenic speech, but also whether they exhibit such disruptions with equal frequency.

Frequency was normed per interaction, rather than being per word count, because the similar clinical setting and virtually scripted nature of each interaction means that occurrence per interview is a valid barometer of overall use. This means that coding 
results for individuals with depression were multiplied by 3.75 so that frequency counts were comparable against those from the larger sample drawn from individuals with schizophrenia. Second, since some features occur over the course of an interaction, rather than as a discrete incident, measuring their incidence per overall word count would be counterintuitive. Sometimes, patients' turns were coded for more than one feature; a sequence in which a patient demonstrates perseveration, for example, is very likely to also include an example of distractibility and excess of content. In other words, a segment of an interaction may contain evidence of two or three different disordered language features. However, each individual feature was only counted in one category. Coding instances of peculiar word choice was aided by the computer program MonoConc Pro 2.2 (http://www.athel.com/mono.html), a concordancer designed to search for patterns in large samples of text. MonoConc Pro was used to determine the lowest-frequency lexical items to aid in identification of peculiar word choice. It was thus possible to identify rare words in a way more principled than simply relying on the judgment of the reader. However, in some cases judgment was an equally valid indicator; a word may be relatively frequent in the corpus, but used once in a way that still marks it as peculiar.

To evaluate the presence of simple syntax I used a sampling procedure because it was unfeasible to code every sentence. Instead, I took three groups of thirty sentences from each corpus (180 sentences overall), with each group representing multiple speakers. I evaluated each sentence in each group as containing zero, one, two, or three or more clauses, and then compared the results between the groups of individuals with schizophrenia and individuals with depression to determine if any patterns emerged. This 
type of sampling procedure has precedent in corpus-based studies and is based on the idea that grammatical feature counts can remain stable across large corpora (Biber et al., 1998, p. 249). It was intended to determine whether a marked difference in clause production between the two groups was immediately evident. As there was no difference, this line of investigation was discontinued.

After each transcript was coded, diagnosis information was reinserted in order to separate those that represent the speech of depressed individuals and those that represent the speech of people with schizophrenia. Finally, the two corpora were compared using the procedures described in section 3.4.

\subsection{Reliability of Feature Identification}

Several of my peers were also given selected transcripts to provide feedback on the validity of feature identification. Five different individuals preparing for graduate degrees from the Department of Applied Linguistics coded conversations using identification criteria similar to that provided in table 3 . Based on their feedback the criteria were revised for clarity.

One consideration in assessing the reliability of this study is the fact that there is a great deal of variability inherent to "normal" speech. This variability is particularly apparent when comparing groups across regions and ethnicities, as has been demonstrated by linguists in the past (see Wolfram \& Schilling-Estes, 1998). As my sample is heterogeneous in terms of geographic region, ethnicity and socioeconomic class, it is impossible to remove the influence of that type of variation. Therefore, it was 
important to conduct a reliability check to ensure that readers could identify characteristics beyond even the great range of behaviors inherent in "normal" speech.

The updated criteria were given to another peer who coded two transcripts. In both cases there were twenty targeted language features that I had coded in advance. The first time she identified fifteen out of twenty correctly, and the second time she identified eighteen out of twenty, 90\% accuracy in the second attempt and 85\% accuracy overall. This exercise demonstrates consistency in the coding process even when feature identification relied on a degree of judgment on the part of the reader.

\subsection{Comparison of Corpora}

The first step in my analysis of the codes was to answer research question one: To what extent are the linguistic behaviors observed in the corpus consistent with what would be expected based on previous studies of schizophrenic speech. I did this by determining whether each of the language features explored in this study was present, as would be anticipated by the relevant literature, and comparing the result against the expectations established by previous research and the diagnostic criteria in the DSM-IV TR (2000). The results of this process are discussed in chapter four, and required no statistical tests.

The second step was to answer research question two: Are the linguistic behaviors observed among patients being treated for schizophrenia significantly different from those observed among patients being treated for depression. For this question, it was necessary to conduct statistical tests. A chi-square test was used to determine if there was a significant difference between groups in situations where categorical data were being 
compared; namely, presence of one or more of the targeted types of disordered speech listed in Table 3 among groups separated by diagnosis, age and gender.

A multiple analysis of variance test (MANOVA) was conducted to evaluate likelihood that the mean differences between groups on individual feature frequency were likely to occur by chance. MANOVA (with Type III sum of squares) was chosen due to the presence of multiple dependent variables and the need to control for inflated chance of Type I errors, as might occur with multiple ANOVAs. The independent variable in this study is whether a speaker belongs to the group of individuals with schizophrenia or individuals with depression; the dependent variables are the various assessments of disordered language features. All assumptions of MANOVA were met except that the results of each feature were not normally distributed within each group. However, MANOVA is "relatively robust to violations," and "departures from multivariate normality generally have only very slight effects on the Type I error rates" (Bray and Maxwell, 1985, p. 33). In other words, it is very unlikely that the statistical significance of my results was affected by the fact that features were not normally distributed within groups.

\subsection{Conclusion}

In this chapter I detailed the specific methodology involved in the completion of my study, from corpora construction to coding and analytical procedures. In the following chapter I will present the results of this study. 


\section{Chapter Four: Results}

This chapter will address the overall results of the study by first briefly examining the question of how many individuals in each group exhibit any of the symptoms of disordered speech, and then exploring each targeted language feature in depth. Section 4.1 reports the overall results of the study. Section 4.2 addresses the results of each individual speech disorder, and section 4.3 summarizes the content of this chapter. Discussion of these results and their implications occurs in chapter five.

\subsection{Overall Results}

Overall the group of individuals diagnosed with schizophrenia exhibited a much greater tendency to produce disordered speech, but there was not a statistically significant difference between groups for every targeted language feature. For the twelve disordered language features examined in this study, an overall analysis found that one or more feature was present in the speech of sixty-seven out of 140 people with schizophrenia (48\%), compared with fourteen out of 50 individuals with depression (28\%). The

difference between the two groups was statistically significant: $\chi^{2}(1, N=190)=$ $5.940, p=.015$. There was no significant difference in the presence of disordered speech based on age, gender or race.

People with schizophrenia exhibited, individually, between zero and thirty-two disordered language features. The average number of features per speaker was 2.62, and there were enough nonsymptomatic speakers that both the median and mode were zero. Depressed individuals uttered between zero and six disordered language features, with an average of 0.34 per speaker. With the exception of the one depressed speaker with six 
features, all other symptomatic depressed individuals exhibited either one or two. The results of the statistical analyses on each feature are described in detail in the following sections as individual abnormalities are addressed.

\subsection{Results by Specific Speech Disorder}

The following sections discuss the findings of this study with regard to two groups of features: Those analyzed for presence and those analyzed for frequency. I will also discuss the findings of my investigation of simple syntax, analyzed in another way. Where relevant, examples from the corpora are provided. All examples are taken from transcripts of interactions with people with schizophrenia.

\subsubsection{Features Analyzed for Presence}

This section discusses the results of features that were assessed on a per-transcript level (presence). The overall results are described in Table 4.

Table 4. Results for disordered language features assessed for presence.

\begin{tabular}{|l|l|l|l|}
\hline Language Feature & $\begin{array}{l}\text { People with } \\
\text { Schizophrenia }\end{array}$ & $\begin{array}{l}\text { People with } \\
\text { Depression }\end{array}$ & Chi-Square Results \\
\hline Word Salad & $2 / 140(1 \%)$ & $0 / 50(0 \%)$ & $\begin{array}{l}\chi^{2}(1, N=188)=.722 \\
p=.396\end{array}$ \\
\hline $\begin{array}{l}\text { Excess of } \\
\text { Speech/Content }\end{array}$ & $22 / 140(15.7 \%)$ & $5 / 50(10 \%)$ & $\begin{array}{l}\chi^{2}(1, N=188)=.987 \\
p=.321\end{array}$ \\
\hline $\begin{array}{l}\text { Poverty of } \\
\text { Speech/Content }\end{array}$ & $19 / 140(13.6 \%)$ & $4 / 50(8 \%)$ & $\begin{array}{l}\chi^{2}(1, N=188)=1.075 \\
p=.300\end{array}$ \\
\hline
\end{tabular}

The least common type of disordered speech in this corpus was word salad, in which any association between output and real-world referents is obscured or completely lost. None of the depressed individuals exhibited this feature, and only two individuals 
with schizophrenia did. The two speakers with schizophrenia that demonstrated word salad seemed disengaged from the conversation for the entirety of their interactions with their doctors and, in fact, a great deal of their speech was completely incomprehensible. A brief excerpt follows:

Patient: The day you weren't here, you said the [UNINTELLIGIBLE]. Doctor: Now, you're his sist, sister-in-law?

Patient: I don't fight him because he's too tall. I ain't going to do that to the chap. No, I've got [UNINTELLIGIBLE].

(Transcript 28255)

In this interaction the patient's responses are unrelated to any input on the part of the doctor; in fact, the excerpt provided above is the most intelligible portion of that exchange. However, this is still not as clear of an example as is found in the literature. There were no instances in which patients' lexical choices were clearly and consistently divorced from any real-world referent; or, at least, if there were any, they were unintelligible.

Both poverty and excess of speech occurred slightly more frequently among people with schizophrenia. Twenty-two out of one hundred and forty individuals with schizophrenia exhibited excess of speech, as opposed to five out of forty individuals with depression. For poverty of speech, the occurrence was 19/140 and 4/40, respectively. However, there was no statistically significant difference between the two groups for excess of speech/content: $\chi^{2}(1, N=188)=.987, p=.321$. Similarly, there is no statistically significant difference between the groups for poverty of speech/content: $\chi^{2}(1, N=188)=1.075, p=.300$. This finding is in direct opposition to the diagnostic criteria for Schizophrenia as articulated in the DSM-IV-TR (2000). 
Poverty of speech/content was simple to identify in these data because patients that provide less than the expected amount of information tend to do so with single-word turns. The following is one example from the corpus.

Doctor: How are you doing?

Patient: Alright.

Doctor: Good? What's new?

Patient: Not much.

Doctor: No? What's new in your life? Not much?

Patient: No.

Doctor: The same things.

Patient: Yeah.

Doctor: Nothing new with work, or nothing, uh Patient: No.

(Transcript 29587)

In this excerpt the patient cuts the doctor off to provide another single-word response, and does not provide the information that the doctor is attempting to elicit. This is a clear example of poverty of content; other patients exhibited something closer to poverty of speech:

Doctor: And, in fact, finish up signing right there. Perfect. Very nice. You have good handwriting, because they'll be able to tell exactly who that is.

Patient: Mistake.

Doctor: Great. no, it's perfect. It's no problem at all.

(Transcript 32521)

This patient indicates that she has made a mistake on a form with the absolute minimum of spoken effort. The remainder of her speech in this interaction is similar; although she participates in the interaction, she rarely produces a full sentence.

In the following interaction, the patient provides too much unprompted information. This is an example of excess of speech/content:

Doctor: If you need anything you just call, okay? Or you tell [NAME OTHER] and have her call.

Patient: She has trouble with her back. 
Doctor: Is that right? Well you tell her hello for me.

(Transcript 33695)

This individual consistently offered excess content throughout the interview.

Excess of speech/content almost exclusively co-occurs with some type of distractibility, and such examples are typically very lengthy (some of which will be discussed later).

\subsubsection{Features Analyzed for Frequency}

This section discusses the results of each investigation regarding each disordered language feature that was counted. Table 5 shows the number of occurrences for each feature; the results have been normed to a sample size of 140 in to take into account the smaller group of speakers with depression.

Table 5. Results for disordered language features assessed for frequency. Values reflect total number of occurrences in each corpus. Results have been normed to a sample size of 140.

\begin{tabular}{|l|l|l|}
\hline Language Feature & $\begin{array}{l}\text { Frequency per 140 } \\
\text { transcripts } \\
\text { (schizophrenia) }\end{array}$ & $\begin{array}{l}\text { Frequency per 140 } \\
\text { transcripts } \\
\text { (depression) }\end{array}$ \\
\hline Glossomania & 12 & 0 \\
\hline Peculiar Word Choice - Overall & 37 & 0 \\
Neologism & 2 & 0 \\
Word Approximation & 25 & 0 \\
Rare Word Choice & 9 & 0 \\
Paraphasia & 1 & 0 \\
\hline Assumed Knowledge & 3 & 3.75 \\
\hline Illogicality & 26 & 0 \\
\hline Distractibility - Overall & 151 & 18.75 \\
\hline Tangentiality & 94 & 15 \\
Derailment & 22 & 0 \\
Loss of Goal & 27 & 3.75 \\
Circumstantiality & 8 & 0 \\
\hline Repetition & 74 & 11.25 \\
\hline Perseveration & 33 & 7.5 \\
\hline Echolalia & 11 & 22.5 \\
\hline Inappropriateness & 28 & 0 \\
\hline
\end{tabular}


Another perspective on the results of my study is contained in the descriptive statistics detailed in Table 6, and overall MANOVA results are reported in Table 7.

Table 6. Descriptive statistics.

\begin{tabular}{|c|c|c|c|c|}
\hline Feature & Group & Mean & Std. Deviation & $\mathbf{N}$ \\
\hline \multirow[t]{3}{*}{ Inappropriateness } & Schizophrenia & .20 & .969 & 140 \\
\hline & Depression & .00 & .000 & 50 \\
\hline & Total & .15 & .835 & 190 \\
\hline \multirow[t]{3}{*}{ Glossomania } & Schizophrenia & .09 & .516 & 140 \\
\hline & Depression & .00 & .000 & 50 \\
\hline & Total & .06 & .444 & 190 \\
\hline \multirow[t]{3}{*}{ Assumed Knowledge } & Schizophrenia & .02 & .145 & 140 \\
\hline & Depression & .02 & .141 & 50 \\
\hline & Total & .02 & .144 & 190 \\
\hline \multirow[t]{3}{*}{ Illogicality } & Schizophrenia & .19 & 652 & 140 \\
\hline & Depression & .00 & .000 & 50 \\
\hline & Total & .14 & .566 & 190 \\
\hline \multirow{3}{*}{$\begin{array}{l}\text { Distractibility } \\
\text { (Overall) }\end{array}$} & Schizophrenia & 1.08 & 2.938 & 140 \\
\hline & Depression & .10 & .364 & 50 \\
\hline & Total & .82 & 2.563 & 190 \\
\hline \multirow[t]{3}{*}{ Unwarranted Repetition } & Schizophrenia & .53 & 1.917 & 140 \\
\hline & Depression & .06 & 240 & 50 \\
\hline & Total & .41 & 1.662 & 190 \\
\hline \multirow[t]{3}{*}{ Perseveration } & Schizophrenia & .24 & .972 & 140 \\
\hline & Depression & .04 & .198 & 50 \\
\hline & Total & .18 & .844 & 190 \\
\hline \multirow[t]{3}{*}{ Echolalia } & Schizophrenia & .08 & .434 & 140 \\
\hline & Depression & .12 & .849 & 50 \\
\hline & Total & .09 & .570 & 190 \\
\hline \multirow{3}{*}{$\begin{array}{l}\text { Peculiar Word Choice } \\
\text { (Overall) }\end{array}$} & Schizophrenia & .26 & .862 & 140 \\
\hline & Depression & .00 & . 000 & 50 \\
\hline & Total & .19 & .748 & 190 \\
\hline
\end{tabular}

Table 7. MANOVA results.

\begin{tabular}{|l|l|l|}
\hline Language Feature & $\boldsymbol{F ~ ( 1 , ~ 1 8 8 ) ~}$ & $\boldsymbol{p}$ \\
\hline Glossomania & 1.376 & .242 \\
\hline Peculiar Word Choice - Overall & 4.687 & .032 \\
\hline Assumed Knowledge & .004 & .952 \\
\hline Illogicality & 4.037 & .046 \\
\hline Distractibility - Overall & 5.497 & .020 \\
\hline Repetition & 2.960 & .087 \\
\hline Perseveration & 1.993 & .160 \\
\hline Echolalia & .194 & .660 \\
\hline Inappropriateness & 2.125 & .147 \\
\hline
\end{tabular}


Glossomania occurred twelve times among the patients being treated for

schizophrenia and not at all among depressed individuals. The difference was not statistically significant, probably because of the low overall frequency of the feature: $F$ $(1,188)=1.376, p=.242$. Glossomania often co-occurred with a form of distractibility, as in the following excerpt, where the patient loses the goal of the conversation as he begins to chain associations together.

Patient: What happened to your cheeks, man, look they're all red. Both of your cheeks by your eyes are red. You know when I was younger, and I was in the Air Force, and when I was a young person, I had sex. You know the worst thing, I think I, uh, did in my life, as far as, uh, things that go in my life was to, uh, get out of the Air Force early. I got an honorable, I got an honorable discharge, fully qualified when I was young, just because of that girl I knew, [NAME OTHER], she wrote me a Dear John letter back when I was [AGE]. I was in love.

Doctor: Yeah.

Patient: I shouldn't have got out. I could've painted curbs and got my stripes. So the sergeant, [NAME OTHER], is going to Colorado, man. So I called him up, he's the one that punched me in the nose, I called him up and I said, "Come over to my apartment, man, and grab some videos before you go." I'll give him those books that I read. There is nothing else I can give him. I don't have that many possessions. You know, my brother, [NAME OTHER], he's the one who works for the paper. He did rather well in his life. He has a family, a house, good profession. So it's like two males against three females. They're the only family that I have, now. So I'm trying to equal the balance. You get two children, and plus they're boys, that's real good. I like boys, man, they're, they're smart. Who else has children? Somebody else has children. You know you has a son? Uh, who knows? I don't see the old [DEIDENTIFIED] people anymore. I don't call them up, [NAME OTHER] and [NAME OTHER]. I called [NAME OTHER] one day, he didn't want to talk to me. He's a, uh, friend of my father. So I'm out of [DEIDENTIFIED] for good, I'm out of [DEIDENTIFIED] for good.

(Transcript 34966)

This patient begins by pointing out the doctor's red cheeks, in itself an example of an utterance inappropriate to the register, which I will discuss later. He then chains a lengthy series of associations together, moving from ruddy cheeks to sex to memories of 
a young love that he associates with his time in the army. He then moves from the military to a specific sergeant, to material possessions, to his brother (who has a large number of possessions), to children, to friends who may also have children, and finally back to the military. This is an example of lexical glossomania as the associations transition rapidly and seem to be triggered by semantic relationships.

Peculiar word choice as an overall category of disordered speech occurred frequently among individuals with schizophrenia. Thirty-seven such examples occurred in the corpus of patients being treated with schizophrenia, and none at all among the corpus of depressed individuals. There was a statistically significant difference between the two groups: $F(1,188)=4.687, p=.032$. Figure 4 displays the frequency of each type of peculiar word choice.

Figure 1. Peculiar word choice by type. All occurrences are among people with schizophrenia.

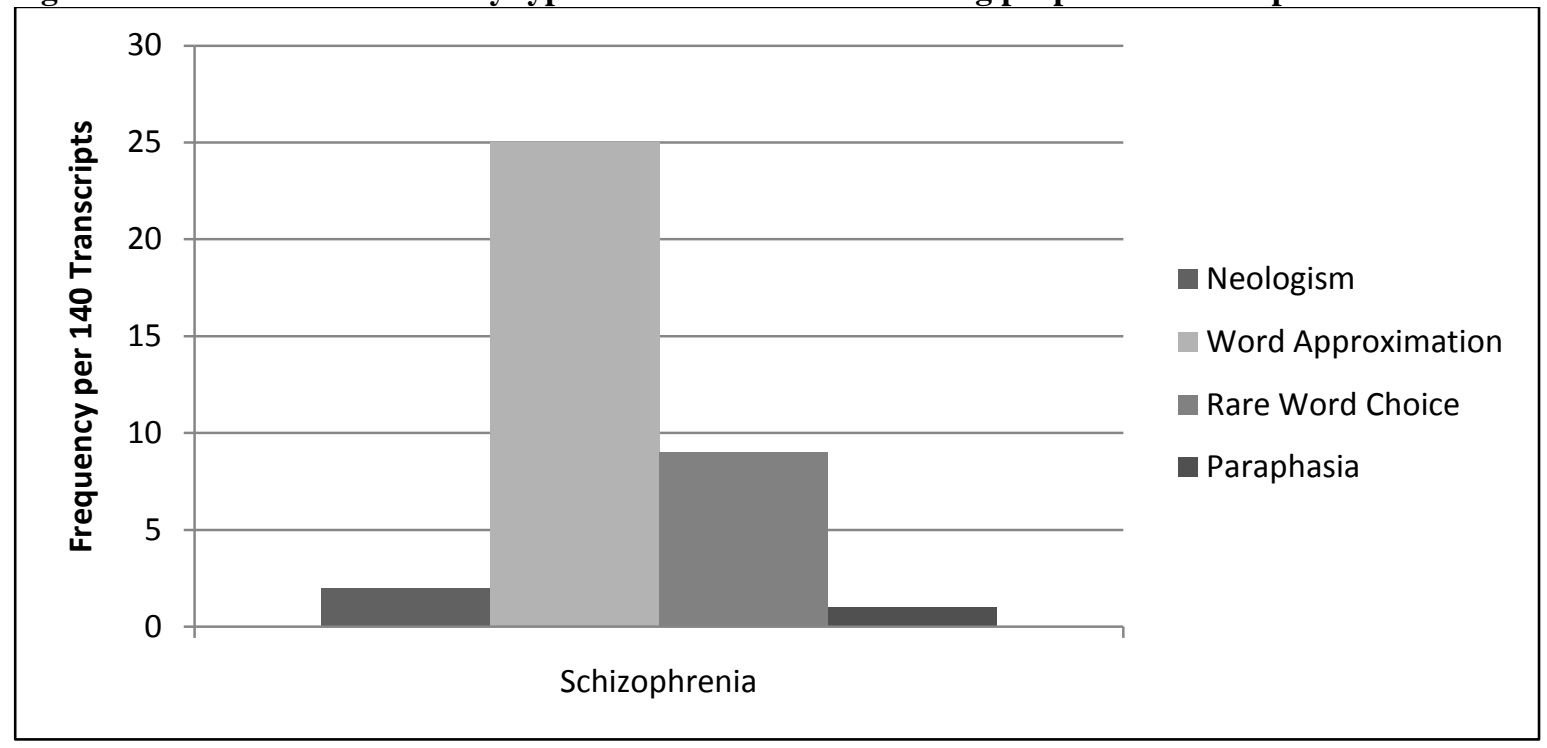

Neologisms and paraphasia proved to be the least frequent, with only three occurrences together. Word approximations were more common, with 25 total, and there 
were nine instances of rare word choice. In some cases, speakers seemed to choose

peculiar words due to confusion regarding the existence or meaning of a lexical item:

Patient: And it looks like he's, and, and it looks like his head is RG cheeks, like you, you, like RGs, like RGs, like, you know, like, RGs, like it's in the summertime?

Doctor: Things like orangey?

Patient: No RGs. You know what RGs is?

Doctor: I don't know what RGs is.

Patient: RGs like in summer time, it's -

Doctor: Like hot, like a heat wave kind of thing?

Patient: Yeah.

Doctor: Huh.

Patient: Like RGs is, not in the winter -

Doctor: Allergies.

Patient: Allergies.

(Transcript 32521)

In this case the patient clearly articulated something that she thought was an acronym -

RGs. Some other examples are either inventions or words that appear to be something

along the lines of "baby talk:"

Doctor: Uh, all right and why are you scratching yourself so much?

Patient: This, there's itchies on me, there's -

Doctor: Yeah, but you're uh, you're making yourself bleed now.

(Transcript 34133)

Doctor: Okay, is something not going right?

Patient: I made a boo-boo.

Doctor: What happened?

Patient: I lost my driver license.

(Transcript 31921)

In both of the above cases, the use of the words "itchies" and "boo-boo" are unusual in

this register. In other cases, patients employ rare words:

Doctor: And you haven't had a relationship as far as I know for some years, right?

Patient: Oh no. I have been benign. I had been the, I'm supposed to be the matriarch of the family, the priest type -

Doctor: Right.

Patient: I'm not Roman Catholic. 
Doctor Uh-huh.

Patient: It's, it, or did I, did I, no, um -

Doctor: You said matriarch, you mean patriarch, is that possible?

(Transcript 28462)

In the above example the patient uses "benign" and "matriarch," both rare words, but uses them incorrectly. In another example, a patient uses "somnolence" in place of "drowsiness:"

Patient: I need more sleep to function and so like, I think I am experiencing somnolence.

(Transcript 56732)

The phrasing of both of the examples above raises the question of whether the rare word choice was simply the result of the context of the interview. The word "benign," after all, is often used in medical discourse, and "somnolence" may have been a term used to describe a side effect. Regardless of cause, however, utterances containing rare words only occurred among individuals with schizophrenia.

Other patients attempt to circumlocute around words that they cannot remember, sometimes creating word approximations or phrases that convey a similar meaning. Both of the following patients struggle with the word "prescription:"

Patient: I should have refills on the, um -

Doctor: Um-hum.

Patient: Thing.

Doctor: Yeah.

Patient: At the drugstore.

(Transcript 32129)

Patient: You know I still have the, uh, the last piece of paper that you gave me for Wellbutrin, too, is that still valid?

(Transcript 34966)

Finally, some individuals employ word approximations that closely resemble morphological errors: 
Patient: And ever since then I've always been feared of somebody behind me always. And here lately it's been worse, like my, my, um, fiancée's sister passed away and, um, in the coffin there was some moments that I looked and it looked like she was sitting up. And it scared me.

(Transcript 12710)

Patient: I have not eaten since last Thursday evening, and I have not hardly drinken anything, drank anything since last Thursday evening because -

Doctor: Well, why, why is that?

Patient: Because if I eat, or drink, or take medications, the demons will be allowed to kill me.

(Transcript 28352)

In both of the above examples, the patients apply an inappropriate suffix and then later correct themselves: "feared" to "scared," and "drinken" to "drank." I have chosen to categorize these as word approximations rather than some sort of morphological disruption for two reasons: first, they are the only examples of their kind, and no other instances exist that resemble morphological errors; and second, there is no support in the literature for disrupted morphology among individuals with schizophrenia. It is also possible that these forms resulted from production pressures, lapses in attention or social variation factors that were not included in this study. However, such features occur only among the group of speakers with schizophrenia.

Issues with assumed knowledge, either too much or too little, proved to be infrequent in both groups; only three examples exist among the corpus of the speech of individuals with schizophrenia, and one among the corpus of speech of depressed people. There was no significant difference between groups for this feature; $F(1,188)=.004, p$ $=.952$. One example follows, as a patient begins to speak to his mother on the phone while at a doctor's appointment:

Patient: Mom, how are you doing?

Doctor: Uh, let me talk to her. 
Patient: Well, I'm here with, uh, are you a doctor?

Doctor: Um-hum.

(Transcript 34133)

This exchange occurred late in an interaction between the patient and a doctor who, based on other content, he seems to have visited several times previously. That the patient would be unsure of whether or not he was a physician seems like a failure of some kind in the patient's knowledge of their environment or working memory.

Illogicality occurred only among patients being treated for schizophrenia, and there was a significant difference between the groups for that feature: $F(1,188)=4.037$, $p=.046$. There were a large number of examples of faulty or inadequate logic among the group of people with schizophrenia, generally co-occurring with some type of distractibility (discussed in the next section). In some cases, this would manifest as a fundamental detachment from cause and effect in regard to event planning:

Patient: I'm getting a shower tonight.

Doctor: You, you're signed up to have a shower tonight?

Patient: No.

Doctor: No? Would you like to have one if you could or not so much?

Patient: No. I'm really not feeling well.

(Transcript 31476)

In the above example the patient doesn't seem to understand that her statement that she would be having a shower that evening entailed that she would have signed up for one and, in fact, would actually be having a shower that night. Another example follows that co-occurs with tangentiality:

Patient: It's never too late, as long as I'm walking on this earth, it's never too late, and I've invested, uh, some time into studying about herbs, and, and, and I know that certain ones you cannot mix, um, um, um, a pharmaceutical medication, so a tea or something, uh, is good for anybody-

Doctor: Um-hum. 
Patient: Like vodka, vodka is an herb, you know, all things like that I, I participate in.

(Transcript 33897)

It is unclear in this case what exactly the patient means by referring to vodka as an herb, but there is no clear logical foundation for her argument.

The most common type of speech disruption among both the individuals diagnosed with schizophrenia and those being treated for depression was distractibility, a category that contains tangentiality, derailment, loss of goal and circumstantiality. One speaker even acknowledged the frequency of distractibility when she lamented the fact that she was "sounding psychotic again" because she was "not completing a thought" (Transcript 28462). There was a statistically significant difference between the groups in overall frequency of distractibility: $F(1,188)=5.497, p=.020$. Figure 2 displays the frequency of each type of distractibility.

Figure 2. Occurrences of distractibility by group and type (normed per 140).

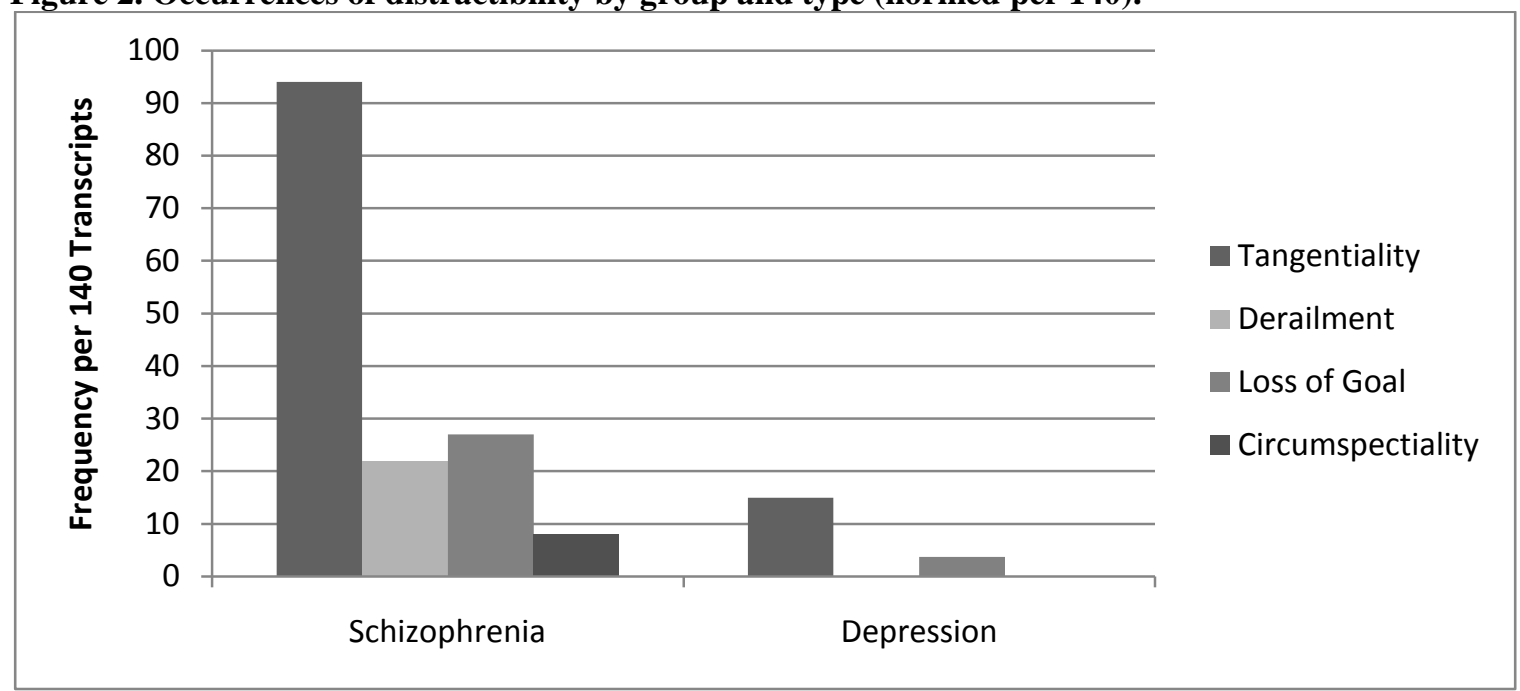


Most utterances displaying distractibility are lengthy. Many, in fact, co-occur with an excess of speech or content. For the sake of brevity, only a few examples will be included below. The purpose of the following exchange is the doctor's attempt to elicit ways in which the patient can change her life for the better.

Doctor: Yeah. Except for the sleepiness, I don't like it and the 5 children, the school will start -

Patient: Yeah, right. See, they take camp now but they can go to camp anytime, you know, so, they're, like, "Oh, you're going to go to, going to take me to camp?" And they don't really, they're not, like, thrilled about it. Uh, it's one of these little camps that they, you know, little center camps here, but, you know, they're, like, "Are you going to take us to camp?" I'm, like, "Yeah, I'll get up in a minute." And I'm just, like, ooh, "Do I want to get up now?" Sometimes I think my mom's house is possessed. Because we've heard horrors stories at her house. They, they've said that there was five dead bodies in the roof and when we first moved in the garage door, it was detached, and there was a big skull, like, spray painted on there. And some kind of weird writing and all. And they've always said that house was possessed. And my mom, she's at home, you know, we're all from up north, we were always very active. Very active. Walking, you know, always. We never depended on a car. And ever since we lived there, my mom, she does not move. She sits in her chair, stays there. And I, and, you know, she sleeps late sometimes. My dad is the same way. Because I've lived on my own before. We live with my mom now, but I've lived on my own and I was fine then. So, it's like when we're there, it's, like, you know, we just, like, uh, lazy like it's possessed with laziness or something. I don't know. Sometimes I feel like that. Just because hearing things and just seeing things about the house. So, I don't know. That might be part of it too. Maybe once we leave there everything will come together. Or maybe it's just the south is not for us in general, I don't know. But yeah.

(Transcript 24358)

The excerpt contains tangentiality, in that the patient goes in a number of different directions, and glossomania; the speaker begins by discussing summer camp, moves to possession and her perception that her house is haunted, then to laziness, her mother, and back to possession. It is also circumstantial, in that the patient finally returns to the point 
at hand but addresses it in only a very roundabout way. In some ways this patient could be said to be derailed, but the following is a more clear example of that feature:

Patient: Well, yesterday, I talked to my sister, [NAME OTHER] take me to [DEIDENTIFIED] again.

Doctor: Oh.

Patient: Got me a newspaper. Have you ever been to the [DEIDENTIFIED]?

Doctor: Yeah.

Patient: What did you get there?

Doctor: I'm not sure.

Patient: I got, next time I go I'll get the egg omelet with toast. I'll bring it back here.

Doctor: Oh, wow.

Patient: I'm going bowling.

Doctor: You're going bowling.

Patient: Not tomorrow.

Doctor: No kidding?

Patient. Not tomorrow. Tomorrow is Tuesday.

Doctor: Yeah.

Patient. Not Wednesday.

Doctor: Okay.

Patient: When will I have blood work again?

(Transcript 29726)

In the above excerpt, the patient is repeatedly derailed; by a location, then by a food item, then by bowling, dates, and finally blood work. It is unclear to what extent these different items are associated. She also demonstrates a form of illogicality, particularly when discussing the days of the week; if there is any meaning behind her reference to Tuesday and Wednesday, it is not explicitly addressed.

Finally, some patients can be said to have lost their goal, wherein they either lose the topic of conversation, forget their own input, or become completely unable to continue a conversational chain. One example follows:

Doctor: You don't like the blood pressure?

Patient: No, I don't want the blood pressure medicine.

Doctor: Okay. Well, I don't see anything on here for blood pressure at this point. That's odd. 
Patient: I didn't say blood pressure. I said for my kidneys.

(Transcript 29726)

The interaction above followed a lengthy exchange in which the patient discussed her dislike of blood pressure medications. Her reference to her kidneys indicates that the patient at some point lost track of the goal of the conversation.

Both unwarranted repetition and perseveration occurred more frequently among patients being treated for schizophrenia than among those being treated for depression (74-11.25 and 33-7.5, respectively), but they occurred only among a small group of patients. There was therefore not a statistically significant difference between the two groups, as shown in Table 6. Unwarranted repetition is characterized by patients repeating information multiple times during an interaction, even when it had already been acknowledged by the physician. One example follows:

Patient: I'm concerned because, you know, um, like I was mentioning to the supervisor, you know, sometimes when people be around others that are disabled, they tend to abuse their position, and a lot of times they, some of the staff talk inappropriately to some, you know, some of the residents and stuff like that. So, I don't, I don't like that.

(Much Later)

... like when people, you know, be around others that are, you know, not able to take care of themselves, they tend to abuse their position, and you know, sometimes you see it after, you know, if people don't watch their behavior, then they tend to take it out on other people because they've been in the current position, you know, dealing with other people for a while. So I just, I just don't trust them.

(Transcript 28901)

The above example rather explicitly demonstrates this patient's repetition of information, even though it had already been discussed in the interaction. The majority of examples of unwarranted repetition are more subtle, consisting of a short phrase or objection that comes up repeatedly. 
Perseveration is characterized by a patient's continuation of a train of conversation despite their interlocutor's efforts to dissuade them. In the following example the patient insults the doctor (a form of inappropriateness, discussed later), causing the doctor to prompt him for information. The patient provides it, but then continues his train of thought.

Patient: Yeah, I got to help my brother out. He's been taking care of me since dad died. He's been doing my taxes. I'm helping them out by fixing up his house. Worse thing about it was that, um, he, he redid his kitchen, his small kitchen, you know my brother's house has ants over there. After all the work of a new countertop in this kitchen, goddamn ants hanging over there. He's got two dogs, two cats, two children, has a mortgage. He's overweight like you -

Doctor: What's your, uh, height?

Patient: 6'1". And he's, uh, my other brother's is going to the mainland in the second week of August, [NAME OTHER], the farmer on the big island. He's going to the big island. I'll never see him again. Called him up and said, "When you leaving?" He quit his job, his, [NAME OTHER] gave my brother, uh, I was in the Air Force with -

(Transcript 34966)

The majority of the interaction quoted above, in fact, consists of the doctor attempting to move on with clinical procedure while the patient provides off-topic input.

Echolalia in these transcripts consisted of immediate echolalia, in that the patient would repeat a portion of his or her interlocutor's utterance in the next turn of the conversation. It was very uncommon among both groups, occurring eleven times among people with schizophrenia and six times among the depressed, although all six instances in the corpus of depressed speech came from a single individual. Even with those discarded, however, there was not a statistically significant difference between the two groups for echolalia. The following speaker with schizophrenia exhibits echolalia with a number of phrases: 
Doctor: Now, um, what brought you in to the hospital?

Patient: Oh, um -

Doctor: Are you hearing voices things like that?

Patient: I'm hearing voices.

Doctor: Okay what are they -

Patient: And it's, it's, it uh, it, it uh, just, just hearing voices and that's, that's it hearing voices. ...

Doctor: Okay, all right uh, when was the last time you were hospitalized some place for psych?

Patient: Last time I was hospitalized?

Doctor: Yeah.

Patient: Uh, uh, last time I was hospitalized. Uh, uh, last time I was hospitalized? For -

Doctor: Yeah, for psych, you know, in one of those psych hospitals.

Patient: Quite, quite a number of times, quite a number of times in the last 17 years.

Doctor: All right. When was the last time, like uh, a month ago, a year ago?

Patient: Uh, but, it, the last time -

Doctor: Um-hum.

PT: Was uh, before last night.

(Transcript 34133)

This patient repeats the phrases "hearing voices" and "last time [I] was hospitalized" several times after they are uttered by the doctor. He also demonstrates a type of distractibility, in that he seems to lose his goal as the interaction progresses and is ultimately unable to answer the question.

Inappropriateness is a category that I created in order to account for certain utterances that seem to fall entirely outside of the register of doctor-patient interactions. In this group I include threats, insults and profanity, of which examples will be provided below. Utterances of this type occurred only among patients being treated for schizophrenia, and not those being treated for depression. However, since a small number of speakers accounted for almost all such examples, the difference between the groups was ultimately not significant: $F(1,188)=2.125, p=.147$. Some examples have already been discussed in other contexts above, but a few more follow: 
Doctor: Well, anyhow, I want to see you back in a week. And you'll see [NAME OTHER] today.

Patient: Who is she?

Doctor: At 2:15. She's a therapist, someone you can talk to.

Patient: She's the one with the crew cut?

Doctor: Well, yes, she's got a crew cut in her back, makes a little bit of a twist. But she's a nice lady. Someone you can talk to.

Patient: All right.

Doctor: All right?

Patient: Is she a lesbian?

Doctor: Uh, you would have to ask her.

Patient: All right.

(Transcript 23708)

This patient's overt inquiry regarding the sexual orientation of a third party seems

inappropriate for this interaction, and the rest of this transcript shows no relevant context or rapport that would support such a question.

Doctor: Um, so [PATIENT NAME]-

Patient: I have a question.

Doctor: Yeah.

Patient: [PHYSICIAN NAME] -

Doctor: Um-hum?

Patient: Can you prescribe me something that, my, my dick, I mean, I like to get a hard on, and I don't have the money for Viagra.

(Transcript 24250)

In this case it is not so much the nature of the patient's request but the way that he phrases

it that seems inappropriate. He returns to this line of questioning several times throughout the interaction.

The following patient appears to have misunderstood the nature of the assistance that this doctor is expected to provide for him:

Doctor: What are you doing to make you feel better?

Patient: Get a job.

Doctor: Or you could take your medicines and-

Patient: Yeah, can you help me with that?

Doctor: End up in the, huh?

Patient: Can you help me with that? 
Doctor: No, I don't have a job. This is a doctor's office, not job office. You have to go to a unemployment office for it.

(Transcript 31408)

Another makes comments that appear to be racially motivated:

Patient: Yeah. So what the hell is this? iPhone -

Doctor: That's the tape recorder, put it down.

Patient: Oh, you're taping this?

Doctor: Yeah, remember I said that's what we were doing.

Patient: All right.

Doctor: 167. (Patient's weight)

Patient: Yeah, these Filipinos, do you, uh, get rid of the other waitress, I mean, uh, secretary?

Doctor: Yeah.

(Transcript 34966)

This patient, in fact, goes on to refer to "Filipinos" in a disparaging way no less than sixteen times in this interaction.

Many more such examples exist, many of which are lengthy; one individual, for example, discusses in detail the financial benefits he will receive after his parents' death, even though such information is unprompted and has no bearing on the topic at hand. Such examples may very well serve as incidents of "unpredictable and untriggered agitation," a diagnostic criterion for schizophrenia according to the DSM-IV-TR (2000). It appears that inappropriate discourse is a characteristic of some speakers with schizophrenia, and further research in this area could be productive.

\subsubsection{Simple Syntax}

After analyzing three samples of thirty sentences per group (180 sentences total), I found that individuals with depression and individuals diagnosed with schizophrenia were roughly equally likely to utter zero and two-clause sentences. Individuals with 
depression, however, were overall more likely to utter sentences with three or more clauses, and individuals with schizophrenia were more likely to utter one-clause sentences. Figure 3 provides a breakdown by clause count.

Although the number of sentences in my sample was small, the proportion of sentences of each length were consistent. Thus, for these patients, simple syntax was not a good indicator of either depression of schizophrenia. However, without a control group of "normal" speakers who are not being treated for mental illness it is impossible to determine whether a small number of clauses is simply a result of the context of a medical interview. In addition, medication could be acting to reduce the likelihood that speakers employ simple syntax. While no strong conclusions can be drawn from this study regarding the validity of simple syntax as a characteristic of the language of people with schizophrenia, the results show a tendency toward low clause count among speakers with schizophrenia. Since previous research has mentioned this feature, further research is warranted in this area.

Figure 3. Number of clauses per sentence

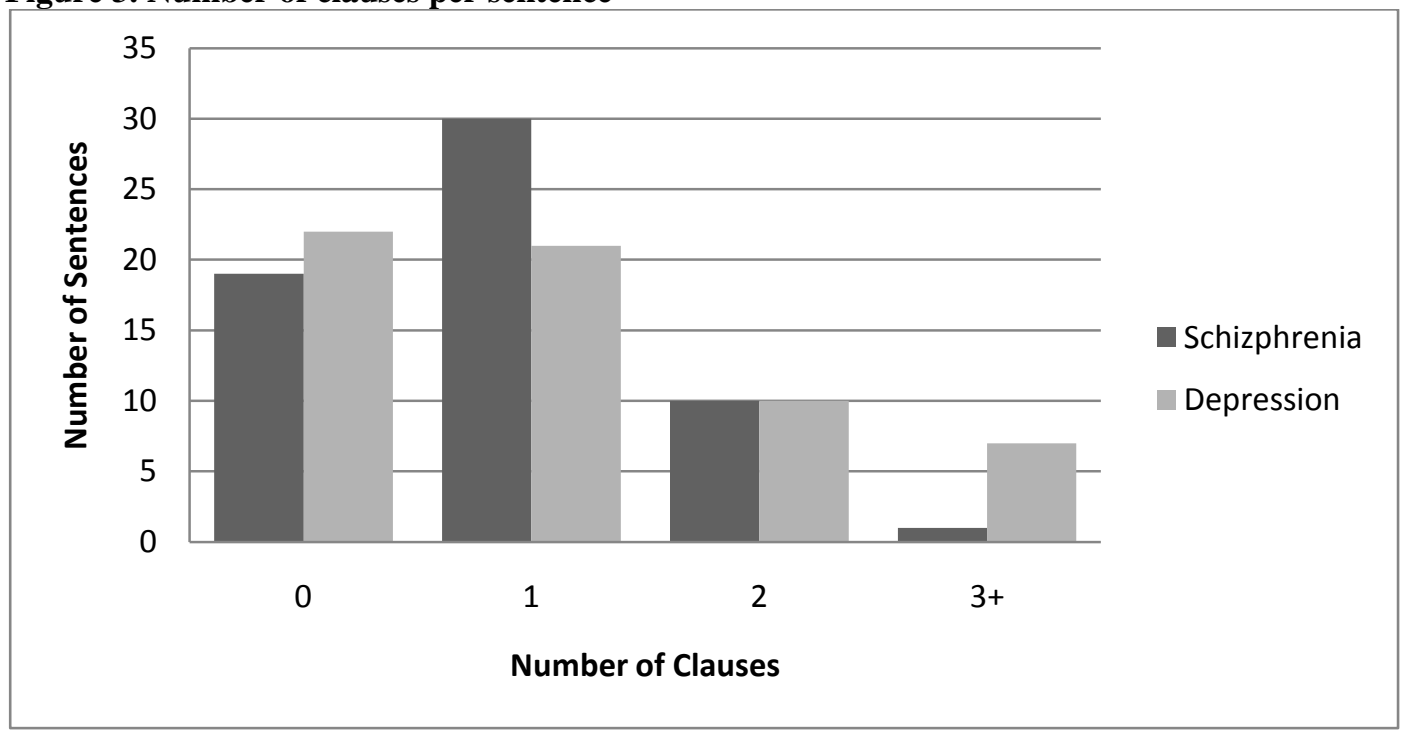




\subsection{Summary}

Every one of the features of disordered language associated with schizophrenia in relevant literature did occur among people with schizophrenia in this study, although only three of them - peculiar word choice, illogicality and distractibility - occur with sufficient frequency to entail a significant difference between the individuals with schizophrenia and the individuals with depression. The next chapter provides further summary of the results, discusses their significance, and presents the implications of the findings. 


\section{Chapter Five: Discussion}

This chapter presents a discussion of the results of my study as well as conclusions based on my findings. Sections 5.1 and 5.2 summarize the results in the context of my two research questions. Section 5.3 discusses the implications of my study for clinical practitioners and their diagnostic criteria, and section 5.4 offers some concluding thoughts, including directions for further research.

\subsection{Research Question One}

To what extent do a large number of individuals with schizophrenia exhibit the behaviors that have been described in small scale studies of the speech of people with schizophrenia?

My first research question was meant to determine whether the types of disordered language discussed in previous studies of individuals with schizophrenia were present among the people that I investigated. This question is perhaps best answered by saying yes; for the most part, the behaviors observed in the corpus are consistent with those that would be expected based on previous research. I found every one of the types of disordered speech that I was looking for among the population of this study, which lends a degree of support to the claim that the language behaviors I looked for are to some degree symptomatic of schizophrenia, at least among medicated individuals. However, some types of disordered speech were very infrequent, which indicates that not all targeted behaviors are common among individuals diagnosed with schizophrenia, and in fact none of them could be said to be predictive or exclusively characteristic of people 
with schizophrenia. This section will discuss the implications of my results regarding some of most frequently-occurring types of disordered speech before moving on to those that are less common.

Distractibility (in all its forms) was by far the most prevalent among the individuals diagnosed with schizophrenia in this research. In fact, it was so common that there were more overall instances of one or more types of distractibility than there were interactions analyzed because many interactions contained multiple occurrences of distractibility. Distractibility was so pervasive among the sample of this study that it makes sense to investigate in future studies whether it is exhibited by every individual with schizophrenia.

Tangentiality was the most common form of distractibility. Derailment and loss of goal were approximately equally frequent, and circumstantiality somewhat uncommon. It is possible that circumstantiality was limited because the medical practitioners in these interactions would often regain control of the interaction before the patient had the opportunity to return to relevance. Any one of the individual types of distractibility was relatively common among the population of this study compared to other targeted language behaviors such as paraphasia.

Glossomania co-occurred without exception with at least one type of distractibility, as well as excess of speech/content. My results indicate that while association chaining (glossomania) is a characteristic of the speech of individuals diagnosed with schizophrenia, it could profitably be evaluated as a member of the subgroup of distractibility. 
Individuals diagnosed with schizophrenia demonstrated both poverty of speech/content (alogia) and excess of speech/content; in fact, they were among the most frequently expressed forms of speech disorder exhibited by this group. It seems clear that individuals diagnosed with schizophrenia can be relied upon to, at least occasionally, provide significantly more or significantly less than the expected amount of information. However, it is minimally confusing and at worst contradictory to claim that individuals with schizophrenia exhibit both excess and poverty. The result of research question two deepens the ambiguity of this result; this symptom will be addressed again in section 5.2.

The high frequency of peculiar word choice among individuals diagnosed with schizophrenia means that, in this case, the answer to research question one is clear: peculiar word choice, particularly word approximations and rare words, are a characteristic of disordered speech among the population of this study. Neologisms and paraphasia, however, were rare, with only three total examples in the corpus. Those two types of peculiar word choice may be infrequently exhibited by individuals diagnosed with schizophrenia, or their occurrence may be inhibited by medication.

Utterances and exchanges that rely on faulty or inadequate logic were common among the population of this study and are likely typical of the speech of individuals diagnosed with schizophrenia. This is a very broad category, and as mentioned above should perhaps include other features of disordered language, such as problems with assumed knowledge. It is likely that abnormality in logic and assumed knowledge are related to what the DSM-IV TR terms "distortions in thought content" (2000, p. 299). The language behaviors characteristic of illogicality preclude some sort of failure in assumed knowledge, in that faulty conclusions are being drawn from information that is 
inadequate or inaccurate. It is important to note that individuals with no psychiatric diagnosis also demonstrate illogicality. However, it is possible that such "normal" illogical statements are based in assumed knowledge that is misunderstood rather than distorted or entirely lacking. In other words, a typical speaker may claim that vodka is healthy, but wouldn't consider it an herb. In addition, sporadic illogicality - or excess of speech, rare word choice, or any other targeted language feature - occur among typical speakers, as shown by any day's average interactions. Speech abnormalities of the type analyzed in this study can only be considered diagnostic of a psychotic disorder if evaluated as one part of a larger pattern of behavior, as discussed in section 5.3.

Unwarranted repetition and echolalia were both present among individuals with schizophrenia, unwarranted repetition particularly so. From these results, it appears that people with schizophrenia have a tendency to repeat themselves in the course of an interaction, and less commonly tend to immediately repeat the utterance of their interlocutor (immediate echolalia). It is unclear the extent to which such repetition is compulsive, or rather if this behavior is once again related to a generally distorted perceptual relationship with the world. More research would be required to determine whether unwarranted repetition among this population simply constitutes delayed echolalia.

Perseveration occurred frequently among the corpus of the speech of individuals with schizophrenia. Resistance to topic shift always co-occurred with excess of content, and often co-occurred with one or more types of distractibility. This behavior is likely the result of the speaker's tendency to provide more than the expected amount of information combined with what the DSM-IV TR terms "impaired social functioning" (2000, p. 299); 
the speaker is not recognizing or not acknowledging their interlocutor's indications that a topic shift is desired.

All of the previous features were relatively common among individuals with schizophrenia, but there are several types of disordered language that manifested infrequently. Only two examples of so-called "word salad" were found among the corpus of individuals diagnosed with schizophrenia, neither of which were as clearly identifiable as examples in the literature. The very small number of such utterances, combined with their ambiguity, may suggest that semantically disassociated language production is not a common result of any type of schizoaffective disorder. In fact, word salad has been described in the literature as a rare form of disordered language (Covington et al., 2005). In addition, it may be that the production of such speech would be inhibited by the fact that the individuals I studied were undergoing psychopharmacological intervention.

Problems with assumed knowledge were infrequent, with only three clear examples among 140 transcripts. If individuals diagnosed with schizophrenia struggle to determine the relationship between their knowledge of the world and the knowledge of others, it is in a more systematic and pervasive way than would be exhibited through utterances that show explicit confusion. Any evaluation of disorganized perception in regards to assumed knowledge would have to occur as the result of observations conducted over an extended period of time. No clear conclusions regarding this behavior among individuals diagnosed with schizophrenia can be drawn as a result of this study. In further research such utterances could productively be included under the umbrella of illogicality. 
Finally, in the case of inappropriateness, research question one can be answered in the negative simply because literature about the language of people diagnosed with schizophrenia makes no mention of utterances that are rude, threatening, insulting, or otherwise inappropriate, but such behavior occurred among the sample I analyzed. However, this result is perhaps more appropriately viewed as outside of the context of the research question; this is an additional piece of information rather than something that directly contradicts the established view. The American Psychiatric Association recognizes that individuals with schizophrenia demonstrate "grossly disorganized behavior" such as "childlike silliness," "unpredictable agitation," and "clearly inappropriate sexual behavior" (2000, p. 299). Inappropriate utterances could be considered examples of this type of disorganized behavior, and psychiatrists should consider adding inappropriate language production as a characteristic of the speech of individuals with schizophrenia.

\subsection{Research Question Two}

Are the linguistic behaviors observed among patients being treated for schizophrenia significantly different from those observed among patients being treated for depression?

The purpose of my second research question was to determine whether the features of disordered language ascribed to individuals with schizophrenia are also present among people with depression. In terms of the overall manifestation of features of disordered language, the answer is yes; there is a significant difference between the two 
groups in regard to the presence of one or more or the targeted features of disordered speech, as reported by my chi-square test of overall symptomaticity. However, as detailed in chapter four, not every individual behavior occurs among either group in a way that constitutes a statistically significant difference. Peculiar word choice, illogicality and distractibility are the only three characteristics for which there was a statistically significant difference between groups (see Table 8). Overall significance is carried by the high relative occurrence of peculiar word choice and distractibility among individuals diagnosed with schizophrenia.

Table 8. Significance of MANOVA Results by Language Feature

\begin{tabular}{|l|l|}
\hline Language Feature & $\begin{array}{l}\text { Statistically Significant } \\
\text { Difference Between Groups? }\end{array}$ \\
\hline Word Salad & No \\
\hline Excess of Speech/Content & No \\
\hline Poverty of Speech/Content (alogia) & No \\
\hline Glossomania & No \\
\hline Peculiar Word Choice & *Yes \\
\hline Assumed Knowledge & No \\
\hline Illogicality & $*$ Yes \\
\hline Distractibility & $*$ Yes \\
\hline Unwarranted Repetition & No \\
\hline Perseveration & No \\
\hline Echolalia & No \\
\hline Inappropriateness & No \\
\hline
\end{tabular}

The key result of this portion is that while all of the disordered language features analyzed in this study occur among individuals with schizophrenia, these types of abnormal language behavior are not exclusively characteristic of psychotic disorders. In fact, individuals with depression (in this study) exhibit many of the same behaviors as those with schizophrenia. This means that clinicians must make diagnostic decisions 
based on more than patients' production of a single feature of disordered language, a perhaps unsurprising conclusion that will be discussed further in section 5.3.

\subsection{Clinical Implications}

As the American Psychiatric Association points out, "no single symptom is pathognomonic of Schizophrenia; the diagnosis involves the recognition of a constellation of signs and symptoms" (2000, p. 299). Whether statistically significant or otherwise, the presence or absence of any single feature of disordered language is inadequate for diagnosis. Ultimately the responsibility for identifying individuals with psychotic disorders rests with psychiatrists, who can evaluate behavior diachronically and holistically. However, linguists can aid them in their task by ensuring that the signs and symptoms related to language are reliable indicators that are unambiguously expressed.

The American Psychiatric Association's Diagnostic and Statistical Manual of Mental Disorders (2000) has the following to say about the speech of people with schizophrenia:

The speech of individuals with Schizophrenia may be disorganized in a variety of ways. The person may "slip off the track" from one topic to another ("derailment" or "loose associations"); answers to questions may be obliquely related or completely unrelated ("tangentiality"); and, rarely, speech may be so severely disorganized that it is nearly incomprehensible and resembles receptive aphasia in its linguistic disorganization ("incoherence" or "word salad"). (p. 300)

The DSM-IV TR also cites alogia (2000, p. 301) as a characteristic of the speech of individuals with schizophrenia, and states that "their speech may be generally understandable but digressive, vague, or overly abstract or concrete" (p. 302), which 
seems a somewhat vague and abstract criterion in and of itself. In sum, the characteristics of the language of people with schizophrenia that are used as diagnostic criteria by psychiatrists are derailment, tangentiality, word salad, poverty of speech and "overly abstract or concrete" speech.

Of those criteria, only derailment and tangentiality (under the umbrella of "distractibility") are present in the population of my study and occur with a frequency that constitutes a statistically significant difference against the group of depressed speakers. Two other features targeted by my study - illogicality and peculiar word choice - are both present and occur with a statistically significant difference in frequency, but they are not mentioned in the diagnostic manual.

Minimally, I believe that illogicality and peculiar word choice should be explored as potential diagnostic criteria, most likely through a second study of unmedicated individuals with schizophrenia. These two features were the most common forms of disordered speech present in my sample of the speech of individuals with schizophrenia, and it seems likely that they would manifest more frequently in the absence of medication. This is particularly true of the more extreme types of peculiar word choice, such as neologisms and paraphasia.

I do not advocate the removal of word salad based on the results of this study, primarily because literature describes it as a rare type of disordered language, which is exactly what I found it to be. However, it receives a great deal more attention than is warranted by its low frequency, probably because of the evocative term used to describe it. Other features for which I did not find a significant difference between groups, such as 
poverty and excess of speech/content, inappropriateness and echolalia can be included, with caveats.

I recommend that the language describing "overly abstract or concrete" speech be revised to more specifically state the language feature in question. In all cases, the nature of each type of disordered speech should be stated as unambiguously as possible in the diagnostic criteria. This is clearly a difficult task; this study, for example, relied on a degree of reader interpretation supported by reliability checks. However, certain disordered language features are supported by this study but go entirely unmentioned in the DSM-IV-TR (2000). The clearest example of this is peculiar word choice in its various forms, which appears to be common among individuals with schizophrenia and should be included in diagnostic materials.

A summary of suggested feature definitions is included in Table 9 , on the following page. Several of these definitions reference Grice's maxims from Studies in the Way of Words (1989), which for brevity's sake will be paraphrased where necessary. A more detailed accounting of Grice's theories is needed to fully justify these revised descriptions, and they ultimately remain subjective in many ways. However, these recommendations are more explicit than previous accounts, and they can serve as the basis for further research that could enable more reliable identification of features particularly those that involve violation of Grice's maxims.

It is important to note that disordered speech occurs on a continuum with otherwise normal behavior, and can be caused by factors other than mental illness, such as environmental stimulation, fatigue, physical context, and a host of other elements that are impossible to predict. The fact that many of these disordered language features occur 
among depressed individuals as well as individuals with schizophrenia is not

diagnostically problematic so long as the individual's behaviors and the context of the

interaction are interpreted holistically.

Table 9. Suggested definitions of disordered language features.

\begin{tabular}{|c|c|}
\hline Name & Identification and Assessment \\
\hline \multicolumn{2}{|l|}{ Syntax } \\
\hline Simple Syntax & $\begin{array}{l}\text { Frequent production of utterances with zero or one clause, defined in this case } \\
\text { by lexical verb count, relative to typical speech. Further research is needed to } \\
\text { determine more precise threshold at which productive syntax is considered } \\
\text { simple. }\end{array}$ \\
\hline \multicolumn{2}{|l|}{ Semantics/Lexicon } \\
\hline Glossomania & $\begin{array}{l}\text { Chains of semantically or phonetically associated utterances that gradually } \\
\text { deviate from the theme of the discourse, ultimately violating Grice's Maxim of } \\
\text { Relation, which requries relevance (Grice, 1989). }\end{array}$ \\
\hline Peculiar Word Choice & $\begin{array}{l}\text { This category should include word approximations, rare words, neologisms and } \\
\text { paraphasia. The functional definitions of these terms can be retained from the } \\
\text { literature, as discussed in Chapter } 2 \text {. }\end{array}$ \\
\hline Word Salad & $\begin{array}{l}\text { Utterances which can be heard but not understood by a native speaker with } \\
\text { normal language function. }\end{array}$ \\
\hline \multicolumn{2}{|l|}{ Pragmatics } \\
\hline $\begin{array}{l}\text { Excess/Poverty of } \\
\text { Speech }\end{array}$ & $\begin{array}{l}\text { Utterances which violate Grice's Maxim of Quantity (Grice, 1989). } \\
\text { Contributions should be no more or less informative than required. }\end{array}$ \\
\hline $\begin{array}{l}\text { Assumed Knowledge } \\
\text { (too little or too much) }\end{array}$ & $\begin{array}{l}\text { Exchanges in which referents are repeatedly introduced or indexed without prior } \\
\text { introduction. }\end{array}$ \\
\hline Illogicality & $\begin{array}{l}\text { Utterances which violate Grice's Maxim of Quality (Grice, 1989). Contributions } \\
\text { should not be false or lack adequate evidence. }\end{array}$ \\
\hline Distractibility & $\begin{array}{l}\text { This category should include tangentiality, derailment, loss of goal and } \\
\text { circumstantiality. The definitions of each of these terms can be retained from } \\
\text { those found in the literature (and discussed in Chapter 2). However, ultimately } \\
\text { utterances demonstrating distractibility are those that violate Grice's Maxim of } \\
\text { Relation, requiring relevance (Grice, 1989). }\end{array}$ \\
\hline Unwarranted Repetition & $\begin{array}{l}\text { Exchanges in which the same information is repeated multiple times without } \\
\text { prompting. The presented information should also have been previously } \\
\text { acknowledged. }\end{array}$ \\
\hline Perseveration & $\begin{array}{l}\text { Exchanges in which individuals persist in a conversational theme despite their } \\
\text { interlocutors' explicit attempts to silence or redirect them. }\end{array}$ \\
\hline Echolalia & $\begin{array}{l}\text { Utterances that precisely repeat a word or phrase from the interlocutor's } \\
\text { previous turn. }\end{array}$ \\
\hline Inappropriateness & Insults, threats and profanity. \\
\hline
\end{tabular}




\subsection{Limitations and Future Research}

The clearest limitation on this study was my reliance on speech produced by individuals who were under the influence of medication to mitigate the effects of their respective mental illnesses, whether schizophrenia or depression. Although the use of speech samples from medicated individuals is common in this field, the most important next step for linguists is to conduct a similar study among a population of unmedicated people with schizophrenia. This would remove at least one reservation about the assessment of extremely disrupted language features such as word salad, neologisms and paraphasia, which were infrequent among the population of my study but may be more common among unmedicated individuals with acute schizophrenia.

The heterogeneous nature of my sample made it impossible to account for language variation due to geographic region, ethnicity or socioeconomic class. Such variation has been demonstrated to exist (see Wolfram \& Schilling-Estes, 1998), and potentially limits the application of my results. Future studies would benefit from the ability to control for sociolinguistic variables. A unifying characteristic among the speakers in my samples is that they were all interacting with practitioners who have a relationship with Verilogue, Inc., but the effect of this condition was also impossible to assess.

Further studies of the speech of individuals with schizophrenia would benefit from the availability of a comparison group that is free of mental illness. I made every effort to minimize the impact of any feature overlap between individuals with schizophrenia and individuals with depression, but at least in the case of simple syntax it is unclear the extent to which my results would be different if compared with a group of 
typical speakers. As it may be difficult to obtain transcripts of "normal" speech in a clinical environment one possible option is to obtain transcripts of the speech of individuals with schizophrenia in a casual environment and compare them to transcripts of individuals with depression in the same.

Any further research should reconsider the subcategorization of features. For example, I recommend that glossomania be included under the umbrella of "distractibility" rather than a discrete diagnostic characteristic of its own. This is because glossomania is, in a very literal sense, an example of a variety of types of distractibility: tangentiality, derailment, loss of goal, and (occasionally) even circumstantiality. Assumed knowledge could also be recategorized as a type of illogicality.

It should be noted that this project is further limited as a result of the decision not to include phonological disturbances, disordered affect, or heightened self-reference and nonverbal reference. A study that more thoroughly evaluates the productive syntax of individuals with schizophrenia would also be needed to accurately evaluate the presence of simple syntax among a target population. Finally, features such as perseveration and inappropriateness should be evaluated in the context of sociolinguistics and models related to politeness and facework. For the reasons above it cannot be claimed that the result of this study is a holistic description of disordered language among people with schizophrenia; rather, it is an assessment of the accuracy of a (substantial) subset of existing claims about the language of individuals with schizophrenia who are undergoing some sort of psychopharmacological intervention. 


\subsection{Conclusion}

An updated description of the speech of individuals diagnosed with schizophrenia is critical to our understanding of related disordered language. Given that the diagnostic manual published by the American Psychiatric Association contains generalizations that are not based on a complete picture of the language of people with schizophrenia, it is very important that modern linguists turn their attention to revising diagnostic criteria that potentially impact more than 70 million individuals worldwide. This project is a first step, but further research is needed. 


\section{References}

American Psychiatric Association. (2000). Diagnostic and statistical manual of mental disorders (Revised 4th ed.). Washington, DC: Author.

Andraesen, N. C. (1986). A scale for the assessment of thought, language and communication (TLC). Schizophrenia Bulletin, 12, 473-482.

Andreasen, N. C., \& Grove, W. M. (1986). Thought, language, and communication in schizophrenia: Diagnosis and prognosis. Schizophrenia Bulletin, 12, 356-359.

Biber, D., Conrad, S., \& Reppen, R. (1998). Corpus linguistics: Investigating language structure and use. New York, NY: Cambridge University Press.

Bray, J. H., \& Maxwell, S. E. (1985) Multivariate analysis of variance. Newbury Park, CA, USA: SAGE Publications, Inc.

Brown, R. (1973). Schizophrenia, language, and reality. American Psychologist, 28, 395-403.

Bruner, J. (1983). Child's talk: learning to use language. Oxford: Oxford University Press.

Chaika, E. (1974). A linguist looks at "schizophrenic" language. Brain and Language, 1, 257-276.

Chen, E. Y. H, Lam, L. C. W., Kan, C. S., Chan, C. K. Y, Kwok, C. L., Nguyen, D. G. H., \& Chen, R. Y. L. (1996). Language disorganisation in schizophrenia: Validation and assessment with a new clinical rating instrument. Hong Kong Journal of Psychiatry, 6, 4-13.

Cohen, B. D., Nachmani, G., \& Rosenberg, S. (1974). Referent communication disturbances in acute schizophrenia. Journal of Abnormal Psychology, 83, 113.

Cohn, M.A., Mehl, M.R., \& Pennebaker, J.W. (2004). Linguistic markers of psychological change surrounding September 11, 2001. Psychological Science, 15, 687-693.

Condray, R., Steinhauer, S. R., \& Goldstein, G. (1992). Language comprehension in schizophrenics and their brothers. Biological Psychiatry, 32, 790-802.

Condray, R., Steinhauer, S. R., van Kammen, D. P., \& Kasparek, A. (2002). The language system in schizophrenia: Effects on capacity and linguistic structure. Schizophrenia Bulletin, 28, 475-490. 
Coupland, N., Coupland, J., \& Giles, H. (1991). Language, society and the elderly: Discourse, identity and ageing. Cambridge, MA: Basil Blackwell.

Covington, M. A., Congzhou, H., Brown, C., Naçi, L., McClain, J. T., Fjordbak, B. S., Semple, J., \& Brown, J. (2005). Schizophrenia and the structure of language: The linguist's view. Schizophrenia Research, 77, 85-98.

Crow, T. J. (1997a). Is schizophrenia the price that Homo sapiens pays for language? Schizophrenia Research, 28, 127-141.

Crow, T. J. (1997b). Schizophrenia as failure of hemispheric dominance for language. Trends in Neurosciences, 20, 339-343.

Fromkin, V. A. (1975). A linguist looks at "A linguist looks at 'schizophrenic language.'" Brain and Language, 2, 498-503.

Gourovitch, M. L., Goldberg, T. E., \& Weinberger, D. R. (1996). Verbal fluency deficits in patients with schizophrenia: Semantic fluency is differentially impaired as compared with phonologic fluency. Neuropsychology, 10, 573-577.

Grice, H. P. (1989). Studies in the way of words. Cambridge, Mass: Harvard University Press.

Habert, B., Grabar, N., Jacquemart, P., \& Zweigenbaum, P. (2001). Building a text corpus for representing the variety of medical language. In: Corpus Linguistics 2001, Lancaster.

Kokkinakis, D. (2006). Collection, encoding and linguistic processing of a Swedish medical corpus. Proceeds of the 5th Language Resources and Evaluation Conference (LREC), Genoa, Italy. Retrieved February 1, 2011, from http://gandalf.aksis.uib.no//rec2006/pdf/23_pdf.pdf.

Pennebaker, J.W., Mehl, M.R., \& Niederhoffer, K.G. (2003). Psychological aspects of natural language use: Our words, our selves. Annual Review of Psychology, 54, 547-577.

Lecours, A. R., \& Vanier-Clément, M. (1976). Schizophasia and jargonaphasia: A comparative description with comments on Chaika's and Fromkin's respective looks at "schizophrenic" language. Brain and Language, 3, 516-565.

Levy, R. (1968). The effect of chlorpromazine on sentence structure of schizophrenic patients. Psychopharmacologia, 13, 426-432. 
Liddle, P. F., Ngan, E. T. C., Caissie, S. L., Anderson, C. M., Bates, A. T., Quested, D. J., White, R., \& Weg, R. (2002). Thought and language index: An instrument for assessing thought and language in schizophrenia. British Journal of Psychiatry, 181, 326-330.

Morice, R. D., \& Ingram, J. C. L. (1983). Language complexity and age of onset of schizophrenia. Psychiatry Research, 9, 233-242.

Moritz, S., Andresen, B. Domin, F., Martin, T., Probsthein, E., Kretschmer, G., Krausz, M., Naber, D., \& Spitzer, M. (1999). Increased automatic spreading activation in healthy subjects with elevated scores in a scale assessing schizophrenic language disturbances. Psychological Medicine, 29, 161-170.

Oh, T. M., McCarthy, R. A., McKenna, P. J. (2002). Is there a schizophasia? A study applying the single case approach to formal thought disorder in schizophrenia. Neurocase, 8, 233-234.

Reichenberg, A., Weiser, M., Rabinowitz, J., Caspi, A., Schmeidler, J., Mark, M., Kaplan, Z., \& Davidson, M. (2002). A population-based cohort study of premorbid intellectual, language, and behavioral functioning in patients with schizophrenia, schizoaffective disorder, and nonpsychotic bipolar disorder. American Journal of Psychiatry, 159, 2027-2035.

Rude, S.S., Gortner, E., \& Pennebaker, J.W. (2004). Language use of depressed and depression-vulnerable college students. Cognition and Emotion, 18, 1121- 1133.

Stirman, S.W., \& Pennebaker, J.W. (2001). Word use in the poetry of suicidal and nonsuicidal poets. Psychosomatic Medicine 63, 517-522.

Titone, D., Levy, D. L., \& Holzman, P. S. (2000). Contextual insensitivity in schizophrenic language processing: Evidence from lexical ambiguity. Journal of Abnormal Psychology, 109, 761-767.

Wolfram, W., \& Schilling-Estes, N. (1998). American English. Maden, MA: Blackwell Publishing. 